\title{
Avalanche activity and socio-environmental changes leave strong footprints in forested landscapes: a case study in the Vosges medium-high mountain range
}

\author{
Florie GIACONA, ${ }^{1,2}$ Nicolas ECKERT, ${ }^{2}$ Robin MAINIERI, ${ }^{3}$ Brice MARTIN, ${ }^{4}$ \\ Christophe CORONA, ${ }^{5}$ Jérôme LOPEZ-SAEZ, ${ }^{1}$ Jean-Matthieu MONNET, ${ }^{3}$ \\ Mohamed NAAIM, ${ }^{2}$ Markus STOFFEL ${ }^{1,6,7}$ \\ ${ }^{1}$ Institut des Sciences de l'Environnement - Université de Genève, 66 bd Carl Vogt, CH-1205 Genève, Suisse. \\ E-mail: florie.giacona@irstea.fr \\ ${ }^{2}$ University Grenoble Alpes, Irstea, UR ETGR, 2 rue de la Papeterie-BP 76, F-38402 St-Martin-d'Hères, France \\ ${ }^{3}$ University Grenoble Alpes, Irstea, UR LESSEM, 2 rue de la Papeterie-BP 76, F-38402 St-Martin-d'Hères, France \\ ${ }^{4}$ Université de Haute-Alsace, Centre de recherche sur les Économies, les Sociétés, les Arts et les Techniques, \\ 68093 Mulhouse Cedex, France \\ ${ }^{5}$ GEOLAB, UMR6042 CNRS/Université Blaise Pascal, Maison des sciences de l'homme, \\ 63057 Clermont-Ferrand Cedex 2, France \\ ${ }^{6}$ dendrolab.ch, Department of Earth Sciences, University of Geneva, 13 rue des Maraîchers, CH-1205 Geneva, Switzerland \\ ${ }^{7}$ Department F.A. Forel for Aquatic and Environmental Sciences, University of Geneva, 66 Boulevard Carl-Vogt, \\ CH-1205 Geneva, Switzerland
}

\begin{abstract}
The medium-high mountain ranges of Western Europe are undergoing rapid socio-environmental changes. The aim of this study is to show that their landscape can be strongly shaped by the actions of avalanche activity, humans and climate. The study area is the Rothenbachkopf-Rainkopf complex, a site representative of avalanche-prone areas of the Vosges Mountains (France). A geo-historical approach documents regular avalanche activity over more than 200 years on 13 paths. A diachronic analysis of historical maps and photographs demonstrates substantial afforestation (from 60 to $80 \%$ of the total surface since 1832). LIDAR data and field surveys highlight the existence of a longitudinal and transversal structure of trees. Hence, the avalanche, human and climate activity footprints are retained by the landscape, which rapidly adapts to these changing drivers. Specifically, the pattern of tree species and heights results from a near equilibrium with regular avalanche activity sometimes disturbed by major avalanches that induce quasi-cyclic changes in the landscape mosaic. The afforestation trend is attributable to profound changes in silvo-pastoral practices, supplemented by the impact of climate change. The wider relevance of the results in relation to the local context is discussed, as well as outlooks that can refine our understanding of this complex system.
\end{abstract}

KEYWORDS: avalanches, climate change, geomorphology

\section{INTRODUCTION}

In mountain areas, forests are structured by multiple factors. Certain of these are internal such as soil type, slope, etc., whereas others exert external pressures: prevailing climatic conditions, forest logging, etc. The patterns of individual trees, forest species and forest stands contribute to the landscape mosaic on the slopes, which is not stationary over time: frequent changes occur in response to changes in human activities and/or climate. Under favourable conditions, snow avalanches or other natural hazards (Benda and others, 1998; Schumacher and Bugmann, 2006; García-Aguirre and others, 2012) generate disturbances which are visible from the level of individual trees to the scale of entire forest stands (Walsh and others, 2004; Simonson and others, 2008; Teich and others, 2012; Feistl and others, 2014). As a consequence, avalanche activity and its variation over time may also contribute to landscape genesis (Malanson and Butler, 1986; Walsh and others, 1994). Hence, the landscape dynamics of a forest slope subjected to avalanches result from the integration over time of the multiple human, climatic and avalanche activity drivers that affected the forest stands during their history. These dynamics are particularly complex, and the visual aspect of the slopes is highly variable over time.

In the literature, the concept of medium-high mountains refers to either an altitudinal stage of high mountain environments or a full topographic entity of modest elevation (Rieutort, 1997). This paper refers to the second meaning of the term. Medium-high mountain ranges are often contrasted to high-altitude mountain ranges in terms of altitude, topography (old versus young mountains, rounded tops versus rugged peaks, etc.), natural processes (seasonal snow cover only versus glaciers) or practices (everyday living space versus marked seasonal rhythm associated with tourism). Their highest elevations are covered by mountainous to subalpine vegetation. They remain preserved wilderness areas but have also been everyday living spaces for centuries, and therefore, possess a rich cultural heritage (Sgard, 2007). In France, this corresponds to the Jura, the Massif Central and the Vosges Mountains whose elevation ranges 
from 600-700 to 2000 m. a.s.I. (Rieutort, 1997). In Europe, identification of such massifs may be more complex. It is clear, for example, for the Swiss Jura or for Sudetenland (Czech Republic), but such identification is sometimes not easy, for example, for the Carpathians. These are the eastern termination of the alpine arc, but their topography and vegetation cover are close to those of medium-high mountains, as we have defined them. Also, a large proportion of the Scandinavian and Russian mountains (Norwegian fjords, Kola Peninsula, etc.) and the Scottish Highlands are very similar to our topographical criteria but are characterised by alpine vegetation because of a harsher climate and they are not densely populated. Yet, all in all, mediumhigh mountain ranges as we understand them, exist in many parts of the world: the northeastern USA, Quebec, northern Japan, etc., but it may be fair to say that, apart from exceptions (e.g. Hétu and others, 2015), they have been overlooked in the scientific literature compared with high mountain ranges (Andes Cordillera, Rocky Mountains, European Alps, etc.), especially in terms of studies concerning snow and avalanches.

However, in medium-high mountain ranges affected by a temperate climate, relations and interactions between human societies, climate and avalanches are particularly strong. Indeed, medium-high mountain ranges are by definition at rather low altitudes $(<2000 \mathrm{~m}$ a.s.l.). Their avalanche paths are, therefore, often forested up to the release areas, and visible marks of avalanche flows (scars, stem morphology, the structure of the stands, specific diversity, etc.) can be found over a wide range of elevations with regard to the elevation of the summits. This situation is less frequent in alpine environments where large proportions of avalanche paths are normally located above the treeline. Moreover, in medium-high mountain ranges, especially in those located in Western and Central Europe, human societies have been present for millennia. Hence, forest ecosystems have long been under pressure by agro-silvo-pastoral, proto-industrial and/or industrial activities. The magnitude of this pressure was variable, depending on the demographic, socio-economic and political contexts, but remained strong overall. The landscape, and especially the presence of forest cover and the characteristics of the stands (species, size of trees, forest density, etc.), has therefore undergone profound and rapid fluctuations during the past centuries. These land cover changes may have had consequences on avalanche activity, but devoted studies remain rare to date and often inconclusive due to a lack of reliable long-range avalanche data. As a counter-example, García-Hernández and others (2017) showed how reforestation since the late 19th century has drastically reduced avalanche damage in the Asturian massif (Spain). Finally, because of their reduced altitudinal range that coincides with the fluctuation zone of the zero-degree isotherm during the winter season, temperate medium-high mountain ranges are particularly sensitive to global warming, with its joint effects on winter snowfall, avalanche frequency/intensity, as well as on forest ecosystems (Beniston and others, 2018).

In the literature, landscape organisation by avalanche activity has been most studied in North America (Patten and Knight, 1986, 1994; McClung, 2003) and/or in typical high-altitude mountain ranges (Viglietti and others, 2010; Anderson and McClung, 2012) where avalanche-forest interactions often remain limited to relatively reduced parts of the whole flow paths and where human influence on the environment has remained limited so far. Also, much of this work was done decades ago (Heath, 1960; Schaerer and others, 1973; Burrows and Burrows, 1976; Luckman, 1977; Butler, 1979; Butler and Malanson, 1985; Johnson, 1987; Butler and Walsh, 1990; Walsh and others, 1990, 1994). Remote sensing and signal processing tools that can accurately evaluate area-wide statistics to sum up landscape patterns were absent at this time. In more recent studies, the focus was often on forest stand adaption to avalanches (Kulakowski and others, 2006, 2011; Voiculescu and Ardelean, 2012), which involved refined analysis of ecological processes at play, but was not conducted at the scale of a whole forest slope due to the amount of refined fieldwork required (e.g. Schönenberger and others, 2005). Alternatively, in different studies, forest landscape patterns and their changes at specific dates were obtained as a byproduct of tree-ring reconstructions of past avalanche activity (e.g., Decaulne and others, 2014; Šilhán and Tichavský, 2017; Favillier and others, 2018; Krause and Kř́žžek, 2018). By contrast, studies specifically addressing the secular evolution of forest landscapes affected by avalanche activity remain rare (Baker, 1992), and those considering avalanches, human pressure and climate together as potential drivers nearly absent (Kulakowski and others, 2016).

On this basis, the objective of this paper is to highlight, using a combination of state-of-the-art tools and methods that the forest landscape of temperate medium-high mountain ranges of Western Europe can be strongly shaped by the action of climate, human activity and avalanche activity. Hence, the main target of the paper is not avalanches and the forest's response to climate and anthropogenic pressure changes. Instead, we aim at characterising and explaining the current state and the evolution over the last two and a half centuries of a complex forest landscape at the scale of a mountain slope as it can be visually grasped in the field. The study is conducted in the Vosges Mountains where secular human-nature relations have existed, as in many medium-high mountain ranges of Western Europe (Boyé, 1903; Dion, 1985). Specifically, the case study is the Rothenbachkopf-Rainkopf complex, a site representative of avalanche-prone areas in the Vosges Mountains

In accordance with the scope of this study, we concentrate on data and forest metrics directly visible on ground photos, aerial photographs and/or maps, that can be evaluated throughout the study area from the data at hand. These metrics are forest extent, forest canopy height and tree species composition. For the current landscape, they are evaluated from field observations (a large sample of trees), airborne laser data and related processing techniques. The long-range evolution focuses on changes in the forest extent as a function of time inferred from a large set of maps and aerial photographs. Aerial photographs have an optimal resolution, but have been available over the last few decades only, whereas historical maps have a coarser resolution but are available for the entire study period. Finally, constructed on the Giacona and others (2017a, b) inventory, refined geo-historical analyses are used to map avalanche activity in the Rothenbachkopf-Rainkopf complex and its interaction over time with human activities and forests. These include exploitation of various sources of historical archives, topographic surveys and field identification of visible marks of avalanche activity in tree stands. This extensive combination of data and methods has proved useful to 
understand that snow avalanches, climate and human influence all play a role in the landscape genesis. Hence, in what follows we show (i) that the current landscape retains the footprint of the actions of these three factors and (ii) that their evolution has been integrated into the rapid and significant changes in the forest mosaic over the past two centuries.

\section{VOSGES MOUNTAINS AND STUDY AREA}

\section{Physical context of the Vosges Mountains}

The Vosges Mountains are located in the north-east of France; they are $\sim 150 \mathrm{~km}$ long and vary in width from 20 to $60 \mathrm{~km}$ (Fig. 1a). The main ridge, oriented north-northeast/south-south-west is composed of a chain of convex peaks culminating at $1300-1400 \mathrm{~m}$ a.s.l. It is the first orographic barrier encountered by atmospheric flows coming from the Atlantic, and it stands perpendicular to the direction of prevailing winds. These winds sweep and blow the snow from the flat and forest-free summits to form cornices (up to several meters) and wind slabs at the top of the eastern slopes, which are marked by a sudden slope rupture (Wahl and others, 2007). The southern part of the Vosges Mountains still has visible marks of the quaternary ice age including glacial valleys, glacial cirques, moraine deposits and slopes $>30^{\circ}$ (Flageollet, 2003).

Because of their latitude and altitude, the climate of the Vosges Mountains is cold and wet, with precipitation throughout the year (climate Cfb according to the KöppenGeiger classification). Average annual rainfall varies between 900 and over $2000 \mathrm{~mm}$ (Drogue and others, 2006). The coefficient of nivosity is 20,30 and $60 \%$, at 700, 1000 and $1350 \mathrm{~m}$ a.s.l., respectively, and the average annual temperature drops from 9 to $4^{\circ} \mathrm{C}$ between 350 and $1400 \mathrm{~m}$ a.s.l. (Wahl and others, 2009). More than 150 frost days are recorded on the summits and snow cover may persist, in the form of firn, until early summer in the glacial cirques on the eastern slopes. Due to these climatic conditions, numerous avalanches are recorded every year in the Vosges Mountains (Giacona and others, 2017a). They occur mainly on the steeper eastern slopes and are often released by the breakage of cornices.

These climatic characteristics combined with topography induce a theoretical organisation of vegetation in three stages. The Collinean vegetation zone exists up to 400$600 \mathrm{~m}$ a.s.l. and is mainly dominated by beech and oak. The mountainous zone is characterised by mixed stands of beech and fir, often accompanied by spruce. Above 1000$1100 \mathrm{~m}$ a.s.l., the subalpine belt is characterised by lowproductivity open forest stands dominated by beeches with twisted and gnarled trunks, as well as summit meadows, the Hautes Chaumes. From paleo-environmental investigations (pedoanthracology), Goepp (2007) has postulated that the Hautes Chaumes were deforested by anthropogenic actions (fires) already during protohistory and that the highest peak of the Vosges Massif (1424 m a.s.l.) is now below the theoretical tree line. However, since the natural tree line is far from being stationary depending on climate and because of the very long and complex history of human activities in the Vosges Mountains (see the section 'Societal context and landscape evolution in the Vosges Mountains'), this is difficult to establish with certainty.

The climate context of the study period expands from the last few decades of the Little Ice Age (LIA, Grove, 1988) at the beginning of the 19th century to the current rapid warming of anthropic origin clearly perceptible since $\sim 1985$. Multiproxy region-wide (Pfister, 1992; Glaser and Riemann, 2009) or gridded reconstructions (Casty and others, 2007) exist, which can be supplemented by a few instrumental series of meteorological observations (Minárová, 2013). This makes it possible to quantify the regional trends having prevailed in annual temperature and precipitation. Sources mostly agree that warming over the study period has been irregular, but very significant over the study period. The study area has also evolved towards a slightly wetter climate (Appendix A).

How these major trends in temperature and precipitation have affected snow amounts in the inner Vosges Mountains remains difficult to evaluate precisely due to a lack of continuous records throughout the study period. However, the few observations and statistical results existing highlight that the characteristics of the snowpack were clearly strongly impacted. Observations made on the Hautes Chaumes at the heart of the coldest decades of the 19th century (Collomb, 1848; Grad, 1871) document the persistence of snow patches throughout the year at that time, which has no longer occurred over the recent decades (Wahl and others, 2009). More systematically, Flageolet (2005) compiled and processed available snow records, highlighting marked drops in the number of snow days, cumulated snowfall and snow-cover duration. He evaluated the decrease at 4060\% over the 1970-2000 period at the lowest measurement stations in the Vosges Mountains (>600 m a.s.l.), whereas, for the highest stations, the decrease over the same period was less (e.g. $-16 \%$ snow days and cumulated snowfall for the Champ du Feu station, 1100 m a.s.I.).

\section{Societal context and landscape evolution in the Vosges Mountains}

Harsh conditions, especially during the LIA, did not preclude from the establishment of human activities, at least seasonal, which has left strong footprints since the Middle Ages (Léser, 1995; Kammerer, 2003; Garnier, 2004). The Vosges Mountains contain resources that have already been developed by proto-industrial activities such as sawmills, glassworks, mines, forges and the metallurgical industry (Jéhin, 1993; Garnier, 1998, 2004). Concomitantly, local mountain societies were known for their agro-pastoralism, in which livestock held a prominent place as the main source of wealth. Mountain farming has two periods: summering in mountain farms, between the end of May and the end of September, and wintering in the valley during the rest of the year. All these activities strongly shaped the Vosges Mountains landscape over the centuries, particularly through the pressure exerted on the wood resource and because of grazing needs. Hence, at the scale of the entire Vosges Mountains, demography, prosperity and forest stand changes are strongly related. Significant clearings occurred during the demographic expansion in the 16th century. In contrast, because of a population decrease linked to war episodes, reforestation occurred in the 17th century. Demographic growth in the 18th century and the renewed development of the Vosges Mountains led to a peak in deforestation at the end of the 18th century. The clearing was related to the needs of mountain dwellers for arable land, pastures, handicrafts, timber and firewood (Dion, 1985; Garnier, 2004). Also, at least until the 19th century, protoindustrial settlements were large wood consumers (Jéhin, 

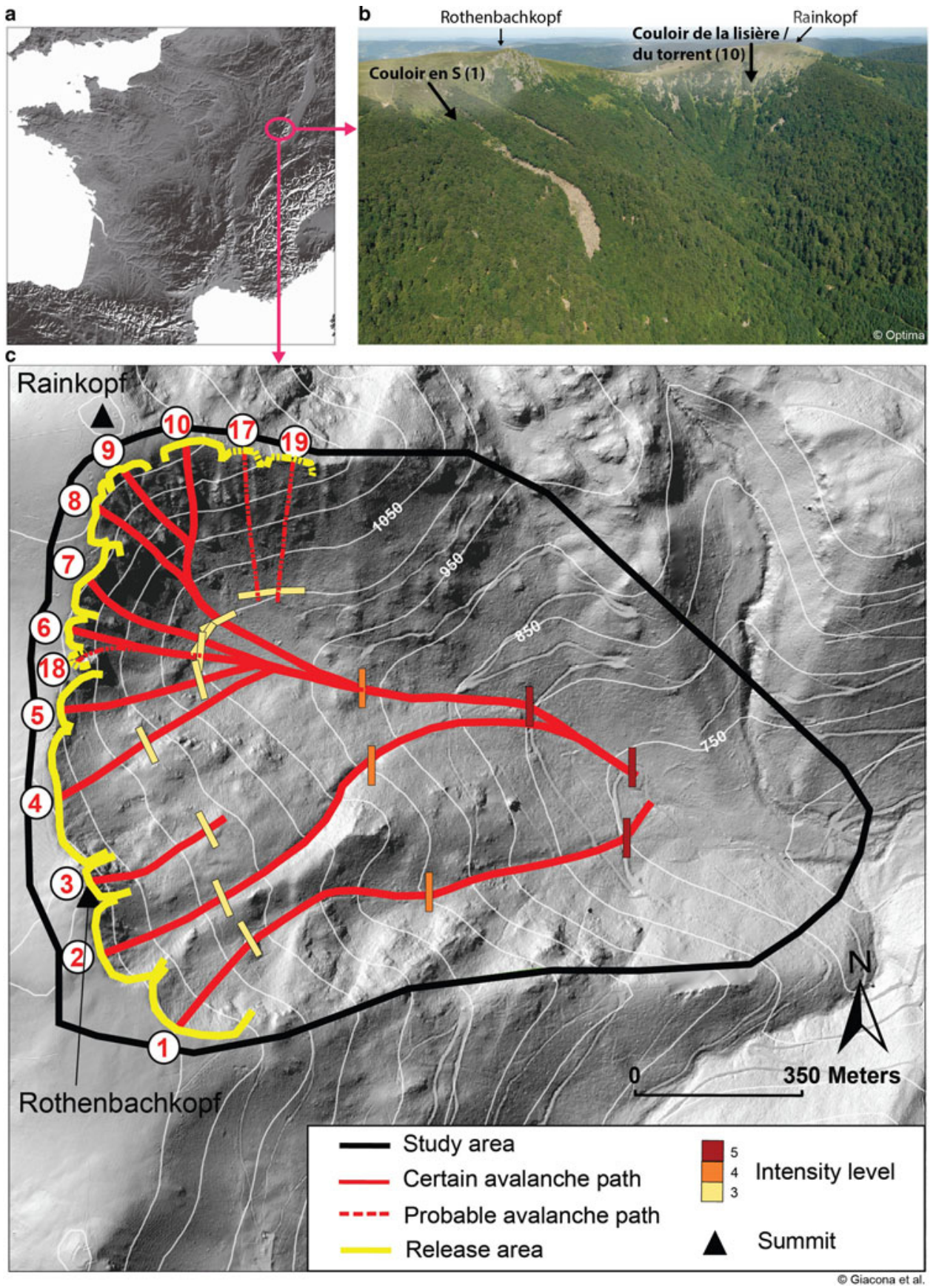

Fig. 1. The Rothenbachkopf-Rainkopf avalanche complex: (a) Location at the French scale, (b) overview of the eastern slopes of the Rothenbachkopf and Rainkopf summits in June 2014, (c) map of the study area with $1 \mathrm{~m}$ resolution LIDAR-based DEM in background. Correspondence between path names and numbers as well as their topographical characteristics are provided in Table 2. At least one event could be retrieved in historical sources for each of the ten certain paths. For the three probable paths, only visible marks of avalanche activity were identified in the field, but no mention of past events was found in historical sources. Intensity levels allow rating individual avalanche events on the scale provided by Giacona and others $(2017 \mathrm{a}, \mathrm{b})$ introduced in the text.

1993, 2010; Garnier, 2004). Finally, as a construction material and fuel, the forests contributed to the war effort until the end of the 18th century (Garnier, 2004). All in all, it is important to note that, since the beginning of its exploitation, the forest of the Vosges Mountains has gone through different successive phases of deforestation and reforestation in relation to highly varying human pressure, which makes the retrieval of its hypothetical 'initial natural state' almost impossible.

However, over the last two centuries, the situation has been somewhat simpler. At the scale of the entire Vosges Mountains, forest cover spread both in valley bottoms and mountains (altitude meadows and glacial cirques). Although this afforestation has accelerated since the 1950s, the process started to become effective at the end of the 19th century, due to the extinction of proto-industrial activities, agriculture abandonment, the rural exodus and a succession of reforestation policies. The latter started in 1801, then continued throughout the 19th century and was still effective in the middle of the 20th century (Departmental Archives of the Haut Rhin department, 7P 48; Brun, 1978; Koerner, 2000; Blanc, 2003). Specifically, agricultural abandonment, rural exodus and the development of the textile industry (Garnier, 1998) caused a marked decline of the pastoral pressure from the second half of the 19th century and even more during the 20th century. Some mountain farms did merge, others (and with them the meadows) simply 
disappeared, which left many ruins after both world wars. Summer cattle were estimated at 4000 cows in the Hautes Chaumes in 1917. It had decreased to 1600 in 1931 (Marthelot, 1952). After WWII, this trend continued, with the number of farms dropping by $40 \%$ between 1955 and 1970, whereas the agricultural population was halved, causing gradual afforestation of abandoned plots.

\section{Avalanche-forest interactions in the Vosges Mountains and the study area}

The biophysical and social characteristics of the Vosges Mountains result in significant avalanche activity (Giacona and others, 2017a, b), which interacts with the forest cover as well as the climatic and social context in a strong but complex manner. For instance, afforestation, warming and the subsequent reduction of snow amounts mentioned above led to the disappearance of avalanches in some lowland areas $(<600 \mathrm{~m}$. a.s.l.). Indeed, the historical enquiry of Giacona and others (2017b) was not able to identify sources relating recent avalanches in certain low-altitude locations of the Vosges Mountains where avalanches were, by contrast, documented during the coldest decades of the 19th century. Field visits confirmed the absence of any visible marks of avalanche activity on these sites (only mature forest stands without any visible perturbations were observed). On the other hand, maintenance of pastoral activity on the summit meadows limits the forest colonisation of areas, which should be, according to Goepp (2007), under the theoretical treeline. This allows the snow to be blown by wind up to cornices, which would favour the persistence of a sustained avalanche activity on the eastern slopes (Giacona and others, 2017b).

The Rothenbachkopf-Rainkopf glacial cirque (1316 m a.s.l. at the Rothenbachkopf summit, $1.7 \mathrm{~km}^{2}$, Fig. 1c) is an ideal case study to analyse these complex processes and to highlight their impacts on landscape dynamics. It has indeed sustained avalanche activity mainly due to the formation of cornices south of the Rainkopf, and east from the ridge linking the Rainkopf and Rothenbachkopf summits (Table 1). It must be stressed at this stage that at the scale of the entire Vosges mountain range, phases of deforestation and afforestation are relatively well known (Garnier, 2004). However, at a much more local scale such as in our study area, this regional trend may not necessarily apply. Local logging pressure may indeed have been at some time very different from what prevailed at the regional scale at the same time. Reconstruction of the forest cover evolution in the study area over the study period from historical maps and photographs was chosen as a means to overcome this difficulty as much as possible.

\section{DATA AND METHODS}

\section{Geo-historical analyses}

In France, systematic surveys of avalanches in medium-high mountain ranges do not exist. Giacona and others (2017b) obtained a geo-chronology of avalanches for the Vosges Mountains by combining archives, oral memory, media articles, various memorial markers and photographs and historical postcards (Fig. 2). This information made it possible to identify 730 avalanches between 1783 and 2014. In Giacona and others (2017b), when possible, avalanches were classified according to their intensity (from 1, very low, to 5, exceptional intensity). A specific intensity scale was used, primarily related to the runout distance. It is adapted to the physical characteristics of the Vosges Mountains so as to reflect the variability of avalanche activity in the study area. Specifically, an avalanche starting from the main ridge and flowing down to the valley bottom is, in the Vosges Mountains, a remarkable avalanche likely to have significant consequences, which warrants a level 5 notation. Second, in Giacona and others (2017b) avalanches causing damage were highlighted. Events recorded up to the mid20th century were almost exclusively damaging avalanches which caused deaths, damaged or destroyed buildings and/ or destroyed large portions of the forest stands.

The specific study reported herein is based on the 60 avalanches that occurred in the study area and are part of this record (see the section 'Avalanche activity and related damage'). For this study, within the study area, numerous specific field visits were conducted to locate the corresponding avalanche paths as precisely as possible. This was done using an in-depth investigation of historical sources referring to observed events coupled with expert analysis of the topography (notably, identification of potential release areas on the basis of standard topographical thresholds, Maggioni and Gruber, 2003), and identification of visible disturbances caused by interactions between avalanche activity and trees. More specifically, the presence/absence of forests, the spatial distribution of species, tree heights and stem

Table 1. Main characteristics of the study area

\begin{tabular}{|c|c|c|}
\hline \multirow[t]{7}{*}{ Topographical characteristics } & Area $\left(\mathrm{km}^{2}\right)$ & 1.68 \\
\hline & Minimum slope $\left(^{\circ}\right)$ & 0.9 \\
\hline & Maximum slope $\left(^{\circ}\right)$ & 49.8 \\
\hline & Mean slope $\left(^{\circ}\right)$ & 26.2 \\
\hline & Minimum elevation (m a.s.l.) & 671 \\
\hline & Maximum elevation (m a.s.I.) & 1304 \\
\hline & Mean elevation (m a.s.I.) & 987 \\
\hline \multirow[t]{6}{*}{ Number of cornice zones and avalanche paths } & Number of cornice zones & 2 \\
\hline & Number of certain avalanche paths & 10 \\
\hline & Number of probable avalanche paths & 3 \\
\hline & Number of avalanche paths where class 3 avalanches can occur & 13 \\
\hline & Number of avalanche paths where class 4 avalanches can occur & 10 \\
\hline & Number of avalanche paths where class 5 avalanches can occur & 10 \\
\hline
\end{tabular}

Certain and probable avalanche paths are positioned in Figure 1. Topographical characteristics of the study area have been computed from the $1 \mathrm{~m}$ resolution LIDAR-based DEM. 

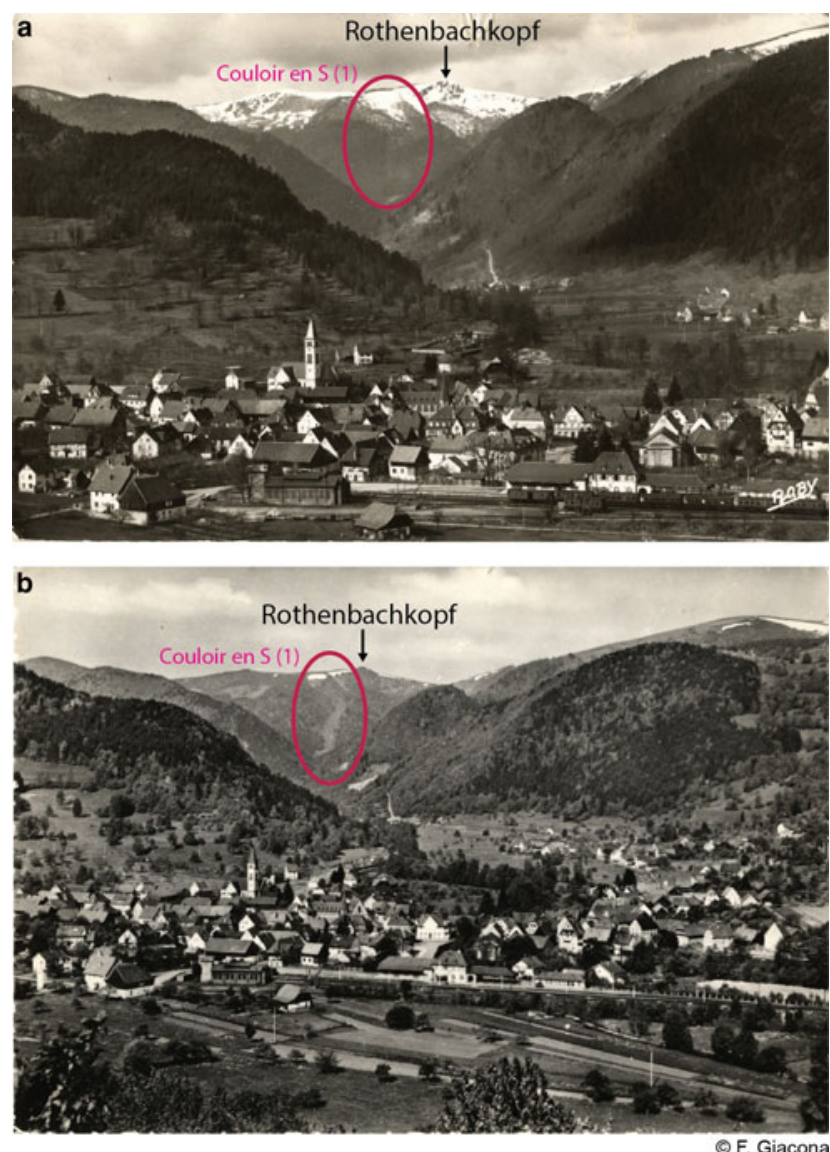

Fig. 2. Postcards of Mittlach (village located in the Munster valley, Alsace region, France) with, in the background, the Rothenbachkopf summit and the Couloir en $S$ (avalanche path number 1 of the study area, circled in red). (a) The flow path is densely forested before the avalanches of February 1952 (R. Herzog edition, circulating in July 1952) and (b) largely open after their occurrence (Société Alsacienne d'Expansion Photographique, Colmar - Ingersheim, July 1964).

morphologies (multiple leaders, decapitation, scars, etc.) were used as indicators to map avalanche-prone areas (Stoffel and Bollschweiler, 2008; Stoffel and Corona, 2014). This all made it possible to determine potential release areas and the main flow paths throughout the study area, and to precisely position intensity thresholds (i.e. the position within the path whose exceedance included the avalanche in a given intensity class). Note that other natural disturbances are truly extremely limited in the study zone. A limited rockfall activity exists on the northern slopes, but its role in shaping the landscape can be considered as rather negligible. As a consequence, even if a few scars or specific stems that were met on the field were potentially attributable to rockfall events instead of avalanche events, this did not preclude identifying avalanche-prone areas.

To further assess the species composition of the forest structure, 1833 trees were pseudo-randomly chosen, identified and positioned with metric precision using a Trimble GeoExplorer GNSS (Global Navigation Satellite System) receiver. This very large field sample covers the whole study zone and all the variability of ages, stands and species that can be encountered when walking across the study area. Although it is nonsystematic, this sampling is considered to represent the specific diversity likely to be encountered, as well as the relative proportions of the different species and their spatial variations within the study area.
Finally, footprints of past human presence were mapped, such as footpaths, walls and enclosures or ruins of mountain farms. These markers were supplemented by various additional historical documents, notably the Napoleonic cadastre (first local edition: 1813), topographic maps and aerial photographs. Combining these with sources related to past avalanche events enabled us to put past avalanche activity within its context (an open or a closed landscape, intensity of the pressure on the wood resource, etc.), to even better grasp the characteristics of specific avalanches (their extension via the location of a destroyed building, for example) and, more generally, to understand the evolution of the study area over the past two centuries.

\section{Airborne laser scanning}

The topography of the study area and the current state of forested slopes were characterised by Airborne Laser Scanning (LIDAR). LIDAR data were acquired by the Institute of Geographical and Forest Information (IGN) in March and April 2011. The vegetation was mainly in leafoff condition, and snow remained on the ground in some high areas. The scanner was an Optech ALTM3100 mounted on a fixed-wing aircraft flying at $290 \mathrm{~km} \times \mathrm{h}^{-1}$ $1500 \mathrm{~m}$ above the ground. The pulse frequency was 71 $\mathrm{kHz}$ with a scan angle of $\pm 16^{\circ}$. The mean point density obtained on the study area was $4.5 \mathrm{~m}^{-2}$. The TerraScan software was used for echo classification in both the ground and nonground categories.

From the classified point cloud, two DEM were computed at $0.5 \mathrm{~m}$ resolution by bilinear interpolation of points classified as the ground at locations of pixel centres. The digital surface model (DSM) was computed by retaining the highest altitude of points in each pixel. The canopy height model $(\mathrm{CHM})$, representing vegetation height, was obtained by subtracting the DEM from the DSM. A smoothed $1 \mathrm{~m}$ resolution DEM was used to extract the topographic characteristics of the avalanche paths identified during the geohistorical inquiry (mean altitude of the release area, vertical drop, etc.; Table 2). Longitudinal and transversal canopy transects were extracted from the $\mathrm{CHM}$ to better quantify the variability of the forest stand height as a function of the location within the study area. Specifically, two transects following the contours at 1000 and $1100 \mathrm{~m}$ a.s.l. were considered. Three longitudinal transects were also drawn: two follow avalanche path profiles and one corresponds to an interfluve zone between two avalanche paths where trees did not show any visual marks of avalanche activity. These transects were chosen to sample the variability of elevation ranges and forest cover heights over the study area (Fig. 3).

To characterise forest cover further in terms of species composition, the classification approach of Eysn and others (2015) was used. A first discrimination was made between conifers and broadleaved trees. In the second step, a distinction was made between pioneer and nonpioneer broadleaved trees. These two distinctions (in two or three classes) are useful to understand forest landscape shaping by avalanche activity. Indeed, after a catastrophic avalanche, in the case of mixed forest stands, reforestation generally involves first pioneer broadleaved trees, then nonpioneer broadleaved trees and eventually conifers. The classification approach proposed by Eysn and others (2015) uses basically the $\mathrm{CHM}$ and a field sample of trees belonging to the target classes. Hence, our field sample was classified in two or 
Table 2. Characteristics of avalanche paths in the study area

\begin{tabular}{|c|c|c|c|c|c|c|c|c|c|c|c|}
\hline \multirow[b]{2}{*}{ Path name } & \multicolumn{7}{|c|}{ Flow path } & \multicolumn{3}{|c|}{ Release area } & \multirow{2}{*}{$\begin{array}{c}\text { Historical } \\
\text { activity } \\
\mathrm{Nb} \text {. of } \\
\text { avalanches }\end{array}$} \\
\hline & $\begin{array}{l}\text { Path } \\
\text { nb. }\end{array}$ & $\begin{array}{l}\text { Length } \\
\text { (m) }\end{array}$ & $\begin{array}{c}\text { Min } \\
\text { elevation } \\
\text { (m a.s.l.) }\end{array}$ & $\begin{array}{c}\text { Max } \\
\text { elevation } \\
\text { (m a.s.I.) }\end{array}$ & $\begin{array}{l}\text { Total } \\
\text { drop } \\
(\mathrm{m})\end{array}$ & $\begin{array}{c}\text { Mean } \\
\text { elevation } \\
\text { (m a.s.l.) }\end{array}$ & $\begin{array}{l}\text { Mean } \\
\text { slope } \\
\left({ }^{\circ}\right)\end{array}$ & $\begin{array}{l}\text { Length } \\
\text { (m) }\end{array}$ & $\begin{array}{l}\text { Mean } \\
\text { elevation } \\
\text { (m a.s.l.) }\end{array}$ & $\begin{array}{c}\text { Mean } \\
\text { exposition }\end{array}$ & \\
\hline Couloir en $S$ & 1 & 1160 & 732 & 1249 & 517 & 976 & 26.4 & 345 & 1236 & NE & 7 \\
\hline Couloir du Torrent & 2 & 1311 & 757 & 1280 & 523 & 996 & 28.5 & 320 & 1266 & NE & 4 \\
\hline Versant du Replat & 4 & 1333 & 768 & 1243 & 475 & 1037 & 26.3 & 377 & 1246 & NE & 9 \\
\hline Combe du Leibelthal & 5 & 1264 & 826 & 1201 & 375 & 1008 & 24.0 & 180 & 1195 & $\mathrm{E}$ & 10 \\
\hline Couloir du Col & 6 & 1245 & 771 & 1199 & 429 & 1001 & 24.4 & 114 & 1198 & $\mathrm{E}$ & 5 \\
\hline Couloir du Chapeau & 7 & 1274 & 767 & 1218 & 450 & 1007 & 25.4 & 255 & 1213 & SE & 5 \\
\hline Couloir Central Rainkopf Sud Est & 8 & 1303 & 765 & 1262 & 497 & 1022 & 28.3 & 201 & 1257 & SE & 4 \\
\hline Couloir 1305 & 9 & 1340 & 745 & 1273 & 528 & 1009 & 28.1 & 127 & 1273 & SE & 2 \\
\hline Couloir de la lisière/du Torrent & 10 & 1349 & 745 & 1272 & 527 & 996 & 27.0 & 180 & 1264 & SE & 3 \\
\hline Versant Rainkopf Sud & 18 & 320 & 1003 & 1233 & 229 & 1113 & 37.1 & 107 & 1228 & SE & 0 \\
\hline Versant Rainkopf Sud bis & 19 & 299 & 996 & 1195 & 199 & 1091 & 36.1 & 136 & 1197 & $\mathrm{~S}$ & 0 \\
\hline Mean & & 1058 & 826 & 1240 & 414 & 1027 & 28 & 202 & 1233 & / & 3.8 \\
\hline Standard deviation & & 428 & 126 & 36 & 128 & 66 & 4.5 & 96 & 31 & / & 3.3 \\
\hline
\end{tabular}

Path numbers refer to Figure 1. Paths 1-10 are certain paths. Paths 17-19 are probable paths. Cornices can develop at the top of all paths, except paths 17 and 19 . All path's topographical characteristics were computed based on the $1 \mathrm{~m}$ resolution LIDAR-based DEM.

three classes. Pioneer and nonpioneer broadleaved trees were distinguished on the basis of the Landolt light index value, an ecological indicator that assigns an integer between 1 and 5 to a given species, describing its potential to deal with light conditions. Here, a threshold of 2 for the Landolt light index was used. In addition to the $\mathrm{CHM}$ and the field sample, classification efficiency was improved with optical infrared colour (IRC) ortho-rectified aerial images acquired in 2010 by IGN. All in all, belonging to a species class was predicted throughout the forested parts of the study area and cross-validation scores were computed with regards to the field sample for both the two- and three-class procedures.

\section{Diachronic analysis}

The changes in forest cover were analysed from aerial photographs and topographic maps (Appendix B). Aerial photographs are available from the mid-20th century. Six photographs were selected: 1951, 1968, 1976, 1984, 2001 and 2010. Topographic maps cover a longer time span with six dates, from 1832 to 2007 . The oldest map used is the

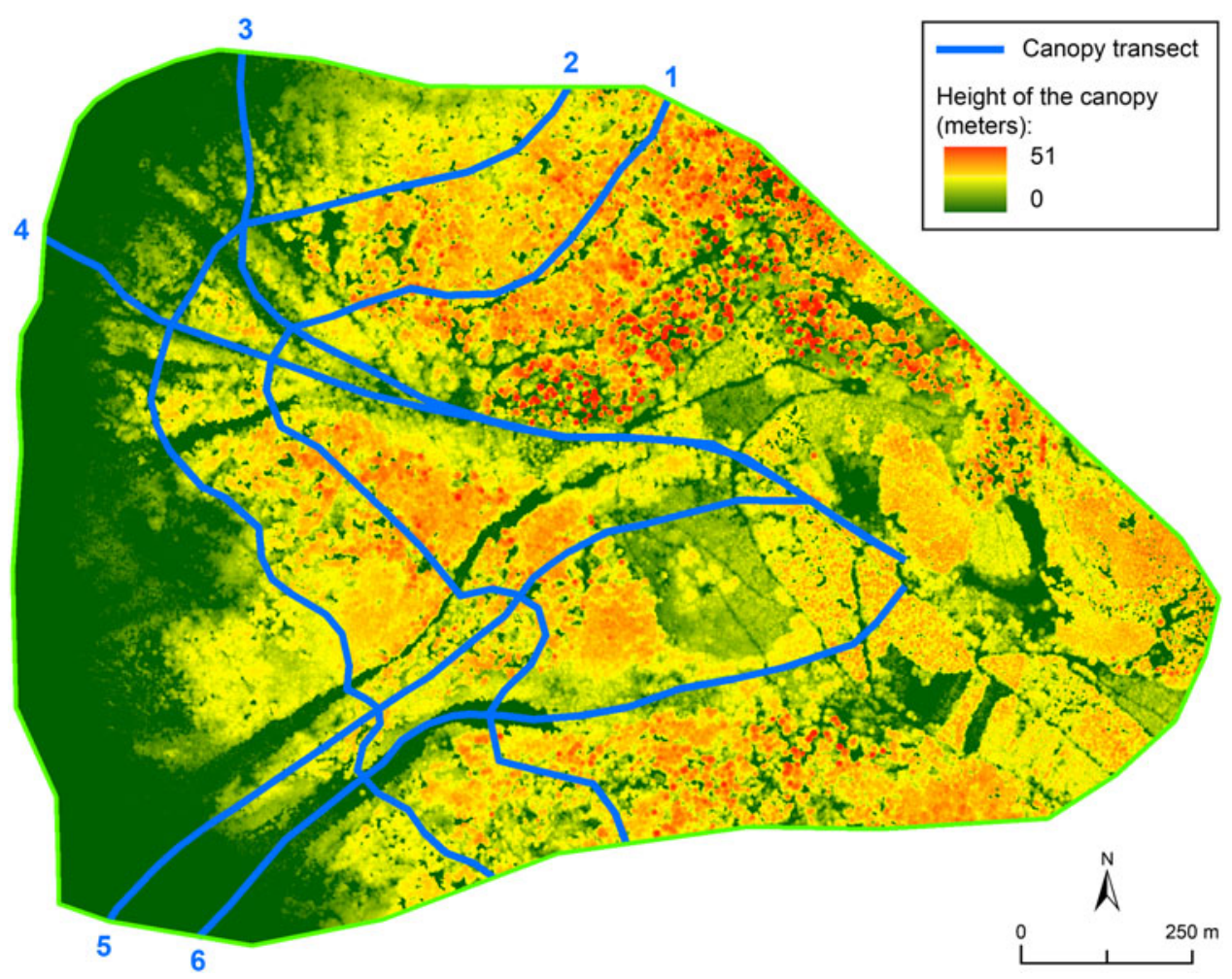

Fig. 3. LIDAR-based canopy height model (CHM) of the study area (March-April 2011). Height of the canopy along transects 1-6 is provided in Figure 7. 
Etat-Major map, the first one sufficiently precise and detailed to map forest cover at the scale of the study area. Other maps correspond to key dates in terms of rural exodus and wars.

Constitution of the topographic map corpus has been difficult because of the complex binational history of the study area. IGN provided the 1832 Etat-Major map and the most current reference map (2007). Other maps were obtained from the Strasbourg University library, from the Club Vosgien (a local hiking association which produced its own maps during a significant part of the 20th century) and from private collections. Depending on the period, the maps were published by IGN, the Karl Flemming Mapping Institute in Berlin and/or the Club Vosgien (Appendix C). Note that, for four out of six maps, the exact date of the topographic survey could not be retrieved. The map is then considered via its publication date. In this case, we cannot exclude a discrepancy with the actual state of the forest areas at the time of the survey, but it is expected to be low (i.e. the Club Vosgien map published in 1968 corresponds to a survey conducted in 1964).

Maps and photographs were geo-referenced (in Lambert93 coordinates). Aerial photographs were previously orthorectified to apply corrections for optical distortions from the sensor system and apparent changes in the position of ground objects caused by the perspective of the sensor view angle and ground terrain. On each document, the forest areas were carefully manually digitised. Comparing these maps with the LIDAR-based DEM then made it possible to derive summary statistics (for each date: forest cover extension, mean altitude, maximum altitude, etc.), which allowed quantifying the forest cover evolution in the study area over nearly two centuries.

\section{RESULTS}

\section{Avalanche activity and related damage}

The study area is affected by significant avalanche activity given that a total of 60 avalanches were identified between winters 1826-27 and 2013-14 by the Giacona and others (2017b) enquiry. A fairly regular occurrence of high-intensity avalanches over nearly two centuries is documented, but overall the frequency of avalanches that were retrieved has increased since the 2000s (Fig. 3).

In greater detail, our combination of refined field, historical and topographical investigations allowed documenting the spatio-temporal characteristics of several of these avalanches more precisely, notably those that caused significant damage. Three avalanches caused casualties in 1850/51 (two persons killed), 1999/2000 (one death) and 2010/11 (one person injured; Table 3). Similarly, avalanches in winters 1826/27 and March 1853 (Fig. 4) impacted the Leibelthal mountain farm that was exploited in the study area at that time (Fig. 5). Historical sources report that the farmer asked for permission to rebuild his farm, which consisted of a cottage and a barn. Specifically, in 1853, he declared that it was 'in the place most exposed to avalanches that have crushed and overflown it five times in forty years' (we could not find any mention of three of these five destructions) and therefore asked for permission to rebuild the farm at another location where it would be 'sheltered from periodic avalanches' (Departmental Archives of the Haut-Rhin department, 7P638: Letter from Mr. Mathias Guthleben, dated 24 May 1853, addressed to the prefect of Haut-Rhin).
Table 3. Typology of avalanche events identified in the study area

Total number of events,

precisely located at the path scale Intensity class

$\begin{array}{lr} & 60 \\ 1 & 50 \\ 2 & 5 \\ 3 & 10 \\ 3.5 & 5 \\ 4 & 2 \\ 4.5 & 2 \\ 5 & 1 \\ \text { Unknown } & 3 \\ & 32\end{array}$

With slight environmental damage

With severe environmental damage

With destruction of one building

With one injured person

With one person killed

With two people killed

Intensity scale is from Giacona and others (2017a, b), briefly described in the text. For each event, intensity classes refer to the exceedance of the intensity levels positioned in Figure 1.

Ruins of the old and the new Leibelthal farms are still visible today (Fig. 5).

The existence of strong interactions between avalanche activity and forests in the study area is reflected in the historical sources by the report of 14 avalanches that caused damage to forest stands. For seven of these, that all occurred after the winter 2003/04, the documented damage was slight. The other seven destroyed (very) large forest stands in winters 1846/47, 1907/08, 1951/52, and 2009/10. At the beginning of February 1952, at least three avalanches destroyed $\sim 20$ ha of forest, leaving more than $3000 \mathrm{~m}^{3}$ of wood deposits (Fig. 2, Appendix D). Sources do not mention whether the avalanches of winter 1826/27 and March 1853 caused significant forest damage. It is possible that the forest beyond the pastures was reached by the flow, but the information was not recorded in the sources consulted.

Among the 60 avalanches identified, 50 could be located precisely at the paths scale. A total of 13 avalanche paths were mapped in the study area, ten of which are known with certainty since one to ten avalanches are documented in each of them by the sources. The three others are considered as probable paths since only visible marks of avalanche activity could be spotted in the field, but no specific mention of past events was found in historical sources (Fig. 1c). Some of the 13 paths already had local toponyms. The others were named for the purposes of this study (Table 2). Nine of the 13 paths converge at $\sim 850 \mathrm{~m}$ a.s.I. Only paths 1, 3, 17 and 19 do not converge with the main system. However, any of the 13 paths is likely to be active independently of the others.

Release areas are oriented mainly north-east to south, and avalanches are likely triggered by the rupture of a cornice (Fig. 1c). Average slope angles of the 13 paths vary between $25^{\circ}$ and $37^{\circ}$. Ten paths have a total length longer than $1 \mathrm{~km}$ and are likely to produce high-intensity avalanches (up to 5) that reach altitudes $<750 \mathrm{~m}$ a.s.l. (Table 2). Three paths are much shorter, $\sim 300 \mathrm{~m}$ long. The maximum possible intensity in these latter paths is estimated at 3 (Table 1), corresponding to avalanches that do not flow below $1000 \mathrm{~m}$ a.s.l.

\section{Current landscape}

The study area is currently largely forested, with the treeline located close to the ridges at $1200 \mathrm{~m}$ a.s.l. According to our 

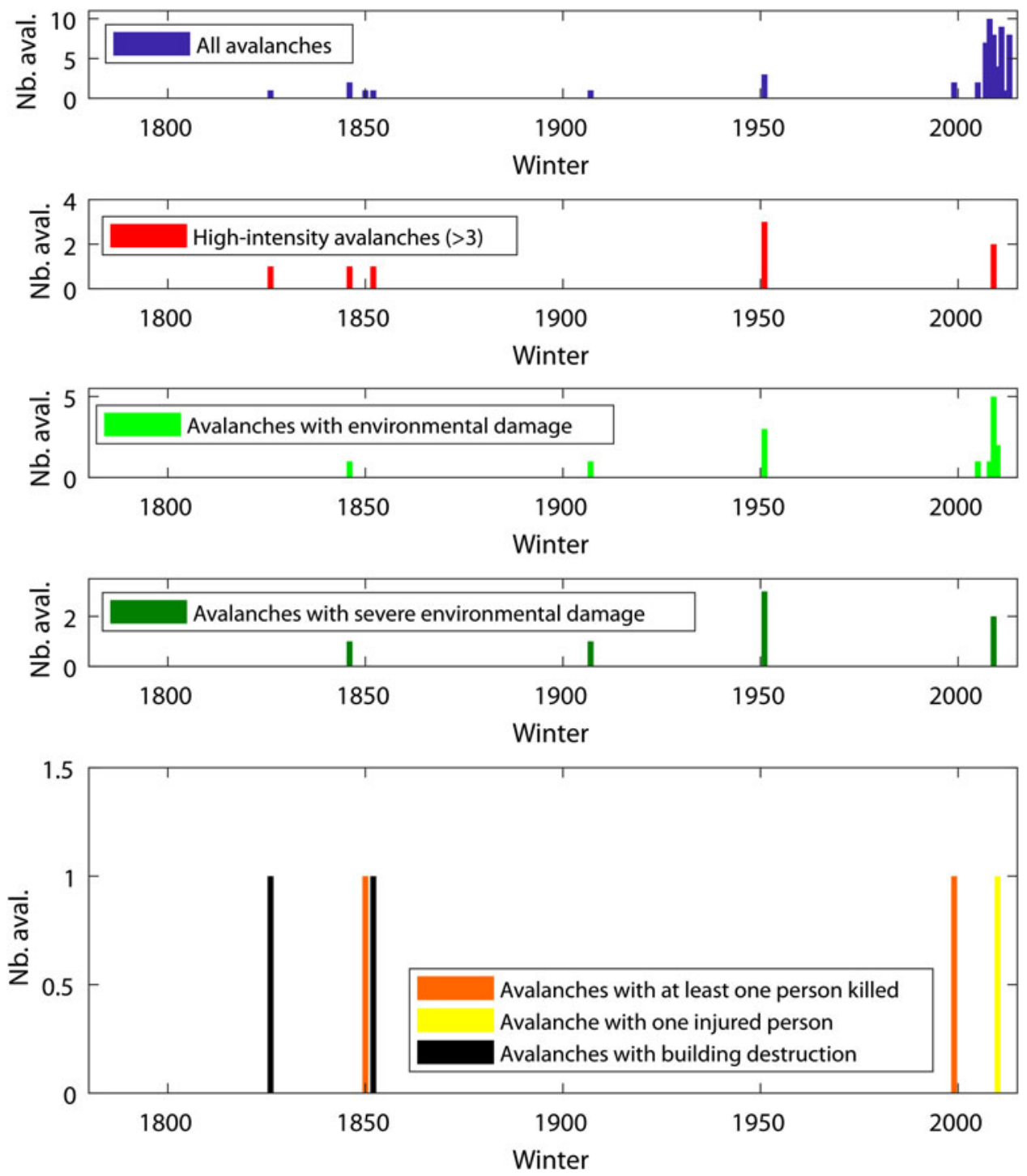

Fig. 4. Chronology of avalanches identified in the study area by the historical investigation. Along the $x$-axis, winter 1800 corresponds, for example, to the period from autumn 1800 to spring 1801. Environmental damage refers to avalanches that disrupted forest stands. Among these, after Giacona and others (2017b) we distinguished as severe environmental damage avalanche events that destroyed large forested areas.

field survey, tree stands are dominated by Fagus sylvatica and Abies alba, which together account for more than $80 \%$ of the trees, almost equally distributed between the two species. Approximately $10 \%$ of the trees are Acer pseudoplatanus. Ten other species of trees and shrubs were identified and were more scarce, each accounting for $<2 \%$ of the total. According to the Landolt classification, six broadleaved species of the field sample were classified as pioneer, whereas only three skiophilous species (Fagus sylvatica, Abies alba and Picea abies) were mapped (Table 4).

In the forest landscape, avalanche paths are visible through quasi-rectilinear forest openings that are easily identifiable in large-scale ground photographs of the area (Fig. 6), in aerial photographs (Fig. 1b, Appendix B) and on the CHM (Fig. 3). The CHM has sufficient spatial resolution to allow visual identification of individual trees, which can reach impressive heights of up to $50 \mathrm{~m}$. Also, the spatial variability of tree heights retrieved from the CHM is very strong, because close-to-zero values are visible along with very high values. This indicates small gaps between large individual trees, demonstrating the high spatial accuracy of the CHM.
Smoothing the CHM with a moving average filter removes this small-scale spatial variability. This provides a better understanding of the spatial structuring of tree heights, namely the zones of the study area where trees are, on average, more or less tall. Along altitudinal transects (Fig. 7), average canopy height increases with altitude from $<15 \mathrm{~m}$ at $1100 \mathrm{~m}$ a.s.l. (Fig. 3, transect 2) to more than 20 $\mathrm{m}$ at $1000 \mathrm{~m}$ a.s.l. (Fig. 3, transect 1). The presence of narrow avalanche paths results in a sudden drop in canopy height. At $1100 \mathrm{~m}$ a.s.l., paths 4-10 induce a reduction in canopy height over $\sim 500 \mathrm{~m}$. Height reduction is much more localised in the case of the extremely narrow Couloir $d u$ Torrent. The Couloir en S is slightly wider and completely deforested in its central part (Fig. 7).

Along longitudinal transect 5 (located on an interfluve between two avalanche paths), the canopy height increases rapidly with greater distance from the release area. It reaches $25 \mathrm{~m}$ at $500 \mathrm{~m}$ and more than $30 \mathrm{~m}$ at $900 \mathrm{~m}$ from the western edge of the study area. Beyond, the height of the canopy drops, reflecting a much younger tree population. Canopy height is quite different along avalanche paths. In the 

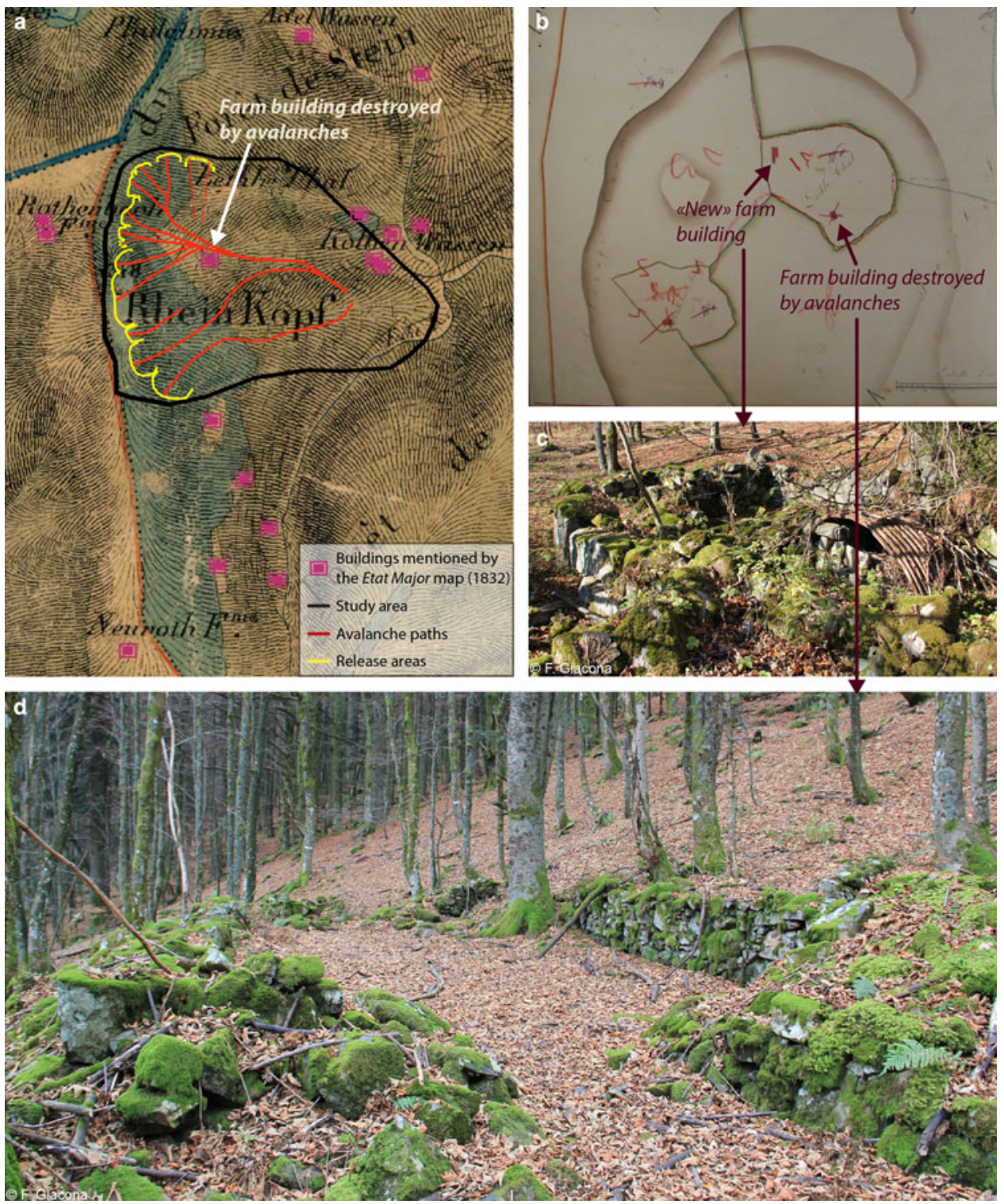

Fig. 5. Material stakes at risk in and around the Rothenbachkopf-Rainkopf avalanche complex: (a) farm buildings mentioned on the Etat Major map (survey in 1832), (b) extract of the cadastral atlas of Metzeral township corresponding to the study area (drawn in 1813, reworked after 1889), (d) 2011 photograph of the ruins of the Leibelthal farm building that was destroyed by avalanches during the first half of the 19th century, (c) 2011 photograph of the ruins of the farm building that replaced it during the second half of the 19th century.

Couloir du Chapeau (transect 4), for example, it reaches 10 and $15 \mathrm{~m}$ at 500 and $900 \mathrm{~m}$, respectively, from the western margins of the study area. Canopy height shows a fairly similar trend in the Couloir de la Lisière/du Torrent, with, for altitudes between 1250 and $900 \mathrm{~m}$, an increase in tree heights well below that observed in zones not impacted by avalanche activity (transect 5). However, the canopy profile is even more disturbed for the Couloir en $S$ (transect 6), with almost no live trees at altitudes above 1000 m a.s.l., which corresponds to the deforested zone clearly visible in Figure 3. Finally, at the bottom of slopes, (<900 m a.s.l), canopy height becomes similar for all transects, which reflects much younger stands whose height is controlled by logging rather than by avalanche activity.

The characteristic organisation of tree species as a function of elevation in the Vosges Mountains is a gradual transition of altitude beech forests near the summits to mixed beech-fir forest at the slope bottom. It still exists in the part of the slopes that are not affected by avalanche activity or logging (Fig. 1c). In avalanche paths, the species pattern is more complex. The beech-fir forest is replaced by pioneer species in active paths (Fig. 8a) or herbaceous species in deforested areas (Figs $9 \mathrm{c}$ and d). Mapping the species classes allows an assessment of the species organisation throughout the study area. Success rates in cross-validation of $79 \%$ (two classes) and $68 \%$ (three classes) were obtained. These rather high values indicate that the mapped classes (Figs $8 \mathrm{~b}$ and c) broadly reflect the empirical distribution of species classes within the field sample (Fig. 8a).

In the immediate vicinity of avalanche release zones, pioneer broadleaved trees predominate. These are accompanied by beech trees of increasing size as one moves downslope. Intermediate altitudes correspond to avalanche paths and runout zones of low-intensity avalanches (up to 3 on our 5-level scale), where beech-fir mixed forests are found. Canopy height and the proportion of conifers rapidly increase as altitude decreases. Altitudes under $1000 \mathrm{~m}$ a.s.l. are reached by high-intensity avalanches only (more than 3 on our 5-level scale). Conifers become dominant and in this area reach their greatest heights. At the lowest altitudes 
Table 4. Typology of tree species identified in the field within the studied area

\begin{tabular}{|c|c|c|c|c|c|c|}
\hline Latin name & Common name & Landolt light index & $\mathrm{Nb}$. & $\%$ & Species class & Species class $\%$ \\
\hline Abies alba & Fir & 1 & 709 & 38.7 & Conifers & 39 \\
\hline Picea abies & Spruce & 1 & 3 & 0.2 & & \\
\hline Pseudotsuga menziesii & Douglas fir & 2 & 2 & 0.1 & & \\
\hline Taxus baccata & Yew tree & 2 & 1 & 0.1 & & \\
\hline Acer pseudoplatanus & Maple & 3 & 200 & 10.9 & Pioneer broadleaved trees & 17 \\
\hline Alnus glutinosae & Alder & 3 & 6 & 0.3 & & \\
\hline Corylus avellana & Hazel tree & 3 & 7 & 0.4 & & \\
\hline Sorbus aucuparia & Mountain-ash & 3 & 48 & 2.6 & & \\
\hline Sorbus aria & Beam & 3 & 30 & 1.6 & & \\
\hline Ilex aquifolium & Holly & 2 & 2 & 0.1 & Non-pioneer broadleaved trees & 44 \\
\hline Carpinus betulus & Hornbeam & 2 & 19 & 1 & & \\
\hline Fagus sylvatica & Beech & 1 & 782 & 42.7 & & \\
\hline Total & & & 1833 & 100 & / & 100 \\
\hline
\end{tabular}

$\mathrm{Nb}$. and \% refer to the number and percentage of trees belonging to the species considered within the analysed sample. The analysed sample of trees is positioned in Figure 8a. Species class \% is the empirical percentage within the field sample of the tree classes mapped throughout the study area in Figures $8 \mathrm{~b}$ and $8 \mathrm{c}$.

(below $900 \mathrm{~m}$ a.s.I.), conifers are even more dominant, but their heights remain more limited due to periodic logging. The species classification also shows comparable gradients from the centre to the margins of avalanche paths, namely from deforested areas occupied by herbaceous vegetation at the centre of the paths to an undisturbed mature forest at the far margins (Fig. 3). Hence, at the species level, avalanche paths are corridors for broadleaved tree species and even herbaceous species to penetrate at lower altitudes (Fig. 8c). This deeply shapes the visual aspect of the forest slopes and its high variability across seasons (Fig. 6).

\section{Landscape evolution over two centuries}

The diachronic analysis of historical maps and aerial photographs allows quantification of the forest evolution in the area since 1832 (Figs 10 and 11). According to topographic maps (Figs $12 \mathrm{a}$ and b), the forest area, $<1 \mathrm{~km}^{2}(\sim 60 \%$ of the surface of the study area) in 1832, increased to $1.35 \mathrm{~km}^{2}$ $(\sim 80 \%)$ in 2007 , passing through a minimum in 1932 (53\%). At the same time, a regular and strong increase of average and maximum forest cover altitudes, on the order of $80 \mathrm{~m}$, is documented between 1832 and 1964 (Fig. 12e). Aerial photographs show an increase of $\sim 35 \mathrm{~m}$ in the maximum altitudes between 1976 and 2010, reflecting recent colonisation of steep slopes in the immediate vicinity of avalanche release areas (Fig. 12f). Both sources agree that, since the mid-20th century, forest cover at intermediate altitudes of the study area has become much denser (i.e. areas without forests have become forested; Fig. 12). All in all, the forest has undergone substantial yet irregular expansion over the last two centuries. Afforestation took place throughout the whole period covered, but predominantly over the second half of the 20th century, resulting in a treeline now just below the ridges, and in a generally closed landscape (Fig. 1b, Appendix B caption D).

In greater detail, changes resulting from avalanche activity can be detected. For example, according to aerial photographs, the forest surface rate of $68 \%$ in 1951 dropped as a result of avalanches in winter 1951/52 (direct destruction, Appendix D, and then post-event silvicultural maintenance) and increased rapidly again after 1976 (Fig. 11b-d). Just before avalanche occurrences, all paths were afforested. In 1968 (first aerial photograph available after 1952, Appendix B, caption C), the large paths of the area were reopened. In 1976, the forest area was minimal, and the delineation of forest areas was very simple, probably due to the exploitation of the slope to clean residual forest breakdowns. Afterwards, afforestation was very rapid, due to the combined effect of natural recolonisation and, probably, plantation of trees intended to erase the stigmas of avalanche damage at certain distant locations of runout zones (Fig. 12). It is noteworthy that avalanches in winter 2009/ 10 (intensity $3-4)$ only slightly affected forest cover $(-1 \%$ between 2001 and 2010; Fig. 12) despite the significant damage observed (reopening of paths 1-2 over fairly large areas; Fig. 10). This highlights in contrast that the effects of the 1951/52 avalanches (intensity 5) were extreme at the scale of the study area.

Changes in forest areas related to avalanche activity are less clear on topographic maps with lower resolution. For example, the impacts of the 1951/52 avalanches are only visible on the 1964 map at the bottom of paths 4-10, and to a lesser extent at the top of paths 8-10. From this example, we can reasonably hypothesise that the opening of paths 4-10, upstream and downstream between 1832 and 1900, and then upstream between 1900 and 1921, at least partially results from the major avalanches recorded in the archives during winters 1846/47 and 1907/08 (Fig. 11, Appendix D).

\section{DISCUSSION}

\section{Landscape organisation in the study area}

\section{Quasi-equilibrium between forest stands and regular} avalanche activity

The avalanche frequency documented by the historical investigation of the study area has been greater since the 2000s. Nevertheless, as in the entire Vosges Mountain range, this certainly reflects a pronounced bias related to sources much more than a natural evolution of the phenomenon (Giacona and others, 2017b). Indeed, during recent winters, the few medium-high-intensity avalanches that were recorded were accompanied by a large number of small avalanches that did not cause significant damage. 

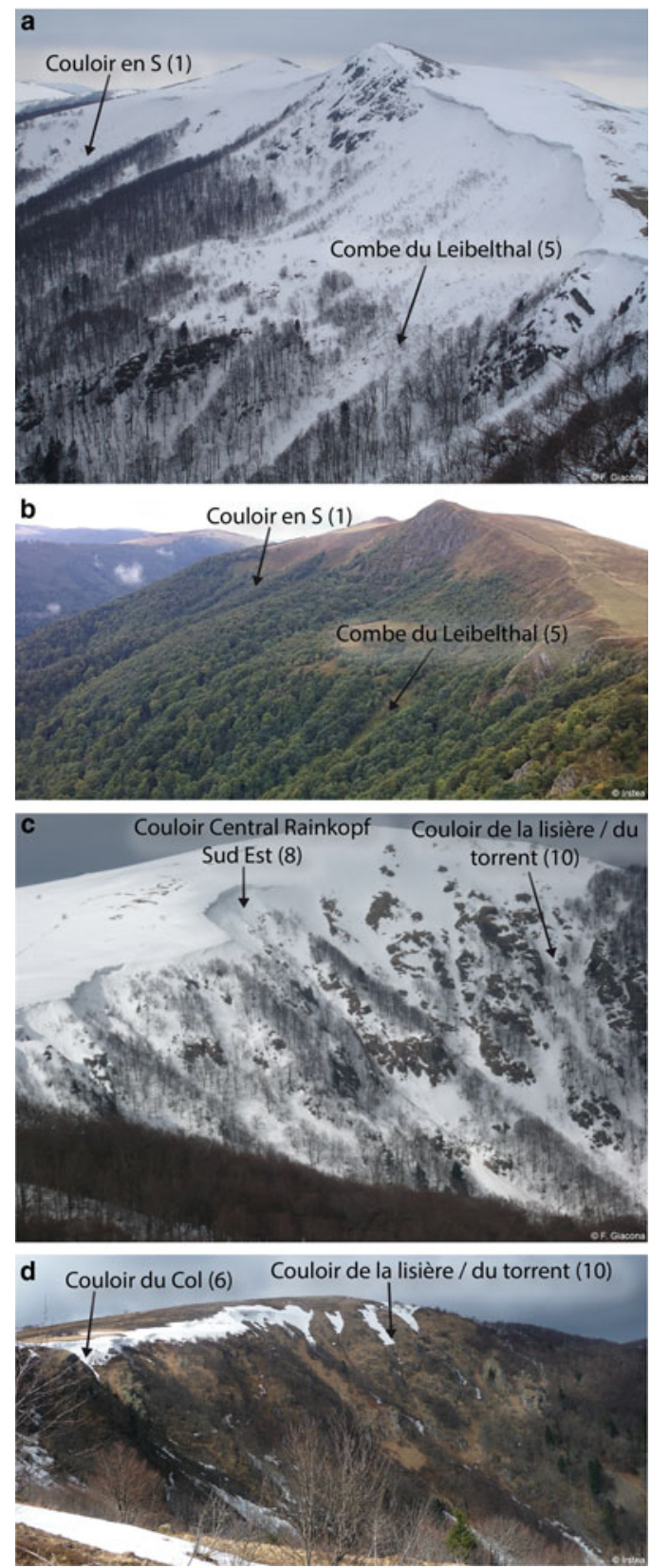

Fig. 6. Visual aspect of the study area over the seasons: (a) in winter 2010, (b) in late summer 2015, (c) in winter 2009, and (d) in late spring 2016. Path numbers and names are provided in Table 2, and localised in Figure 1.

Over the whole study period, the record of large avalanches and/or avalanches having caused damage is fairly regular. It is, therefore, very likely that low-intensity avalanches also frequently occurred in the area throughout the entire study period but were not retrieved in the sources.

From a spatial point of view, the historical enquiry identified past events on all except three paths of the study area. In addition, on all 13 paths of the study area, clear visible marks of (rather) recent avalanche activity were identified by field visits. As a consequence, all the study area's paths may still be active, even if it cannot be excluded on the basis of the data analysed here that, at least for a few paths, avalanche activity is now less strenuous than it was earlier (see the section 'Landscape evolution linked to changing human pressure and climate'). This situation differs from the lowest elevation sites of the Vosges Mountains where Giacona and others (2017b) found no proof, either in historical sources or in the field, of recent avalanche activity.

At the same time, the current forest landscape was described through the forest canopy height and the species composition (our two- or three-species classes). These two metrics were evaluated in the entire study area by combining field visits and LIDAR data. They truly characterise the largescale visual aspect of the slopes which we aimed to describe and understand. It appeared that the natural altitudinal zonation of the tree stands (heights and species composition) remains visible only in the areas that are not (or very rarely) affected by avalanche activity. Elsewhere on the slopes, the forest structure is considerably different, which leads to the conclusion that avalanche activity is indeed a significant driver of the aspect of the forest landscape in the study area. Specifically, forest stands present patterns that are longitudinally and transversely structured by the position of avalanche paths. The visual aspect of these patterns varies across seasons as a function of the species composition. Hence, except in the Hautes Chaumes and in the lowest altitudes of the study area where avalanche activity is almost absent and where the landscape reflects above all pastoral and forest exploitation, avalanche activity plays a major role in the landscape genesis. We, therefore, postulate that the landscape organisation of the area results primarily from a quasi-equilibrium between forest stands and avalanche activity (frequency of impacts, flow velocity pressure and maximum height). In other words, the greater the avalanche activity, the more one finds individuals, stands and species that are able to cope with the impacts (resilience to impacts via flexion, wound healing, adoption of specific morphologies, etc.).

Field observations in favour of the existence of such equilibrium have already been documented by several previous studies (e.g. Malanson and Butler, 1984; Veblen and others, 1994; Rixen and others, 2007). We arguably contribute new evidence of this in the context of a mountain range where interactions between avalanche activity and forest stands are exacerbated since the treeline is close to or even above the release areas. In addition, our results were obtained using a combination of methods, including LIDAR data processing, which has been, to our knowledge, rarely used for this purpose to date. This allowed computing detailed forest metrics over the whole zone, which supplemented more traditional field surveys and allowed an area-wide investigation of the forest landscape. Hence, our approach appears to be a useful complement to most of the recent studies that privilege small-scale investigations of avalanche-forest interactions and their ecological consequences on forest stands (e.g., Schönenberger and others, 2005; Bebi and others, 2009).

\section{Landscape opening - closure cycles due to major avalanches}

Geo-historical and diachronic analyses show that the equilibrium between forest stands and avalanche activity is, in the study area, fairly regularly disrupted by exceptional avalanches. These high-magnitude events destroy stands often reached by less severe avalanches and which are, therefore, according to Feistl and others (2015), more or less resilient to impacts. They also reach mature stands located outside usual avalanche-prone areas. As documented - for example, Takeuchi and others (2011) for a case study in Japan - the result is an opening of the landscape over large and wide 

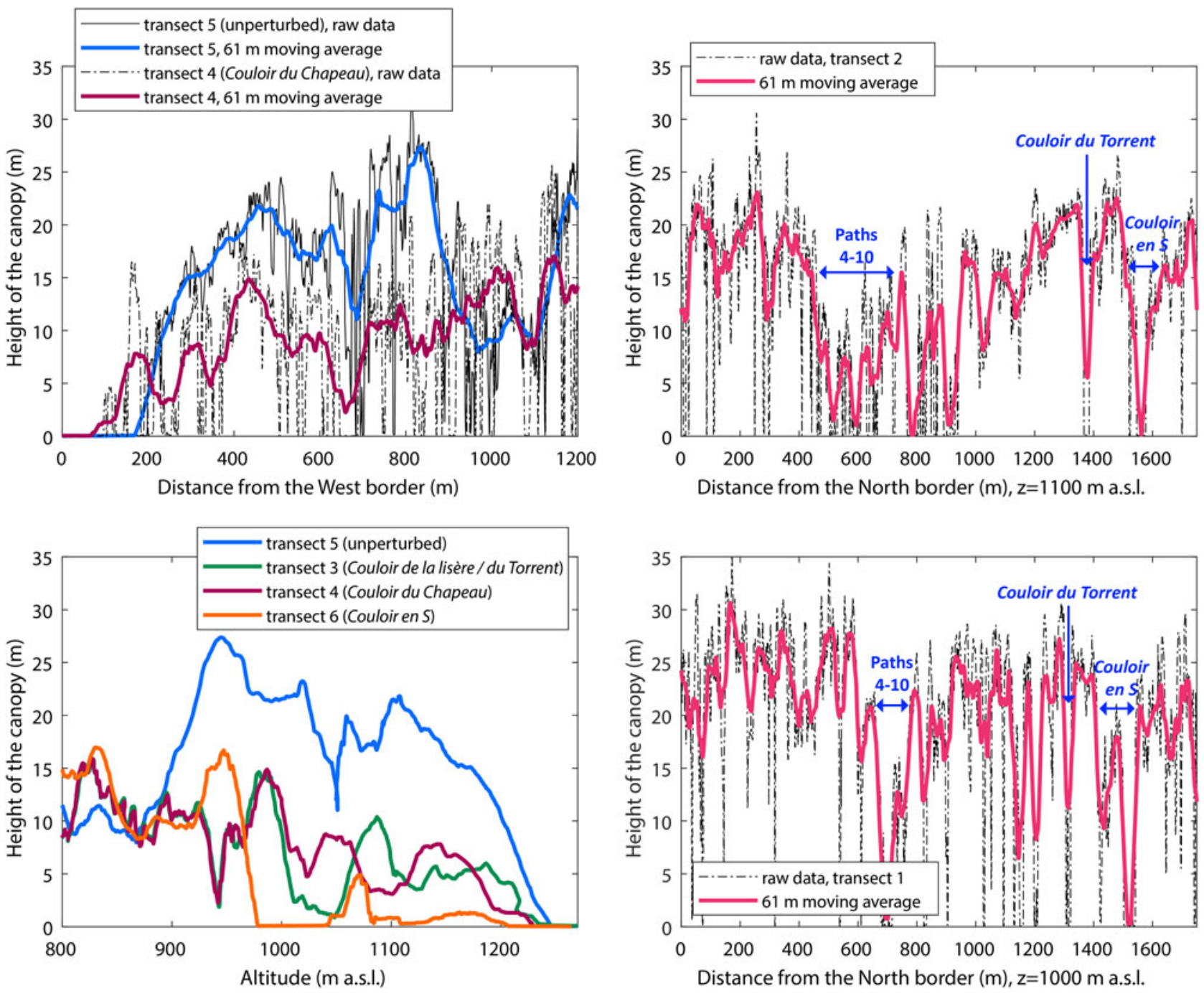

Fig. 7. Height of the canopy in March-April 2011 along transects of the study area. Transect numbers correspond to Figure 3. Canopy heights were evaluated along transects from the CHM (Fig. 3). Path numbers correspond to Figure 1 and path names to Table 2.

areas (Fig. 2), at the end of which a large volume of wood is deposited (Fig. 9). At this abrupt opening of the landscape follows a re-closing of the landscape spanning a few decades.

Over the entire study period, this type of cycle seems to have occurred four times, following the major avalanches documented during the winters 1846/47, 1907/08, 1950/51 and $2009 / 10$. The last cycle is in progress, with the re-colonisation of the post-event landscape already started (Fig. 9e). The previous cycle, following the even greater number of avalanches of winter 1950/51, was well documented with aerial photographs. In $<50$ years, the devastated paths have been totally re-closed (Fig. 6). The data available regarding the two previous cycles is more tenuous. Nevertheless, sources clearly describe the magnitude of avalanche damage in winters 1846/47 and 1907/08 (Appendix D), and historical maps suggest that local openings in some paths occurred (Fig. 10) at a time when the overall dynamics of landscape closure was already in place. Of course, we know that a large fraction of the avalanches that actually occurred long ago is missing in the chronology illustrated in Figure 3. On the other hand, we are rather confident that most, if not all, major events that occurred over the study period were retrieved. Hence, we postulate that winters generating avalanches of sufficient magnitude to heavily damage forests seem to have occurred fairly regularly in the zone over the study period, every 50 years or so (that avalanches that caused severe environmental damage in Fig. 3).

All in all, avalanche activity structures the forest landscape of the zone not only through equilibrium in which the location of the different stands does not change over time. In addition, the slopes evolve in a quasi-cyclical manner, where the observable landscape depends on the time of the openingclosing cycle. In particular, the characteristics of stands (size of the individuals, species) visible at a given location evolve over time according to the growth rates of tree individuals and the ability of species to recolonise cleared spaces. As a consequence, the landscape of the study area has a high spatial but also temporal variability, with the recolonisation areas characterised by an ever-changing gradient of species, morphologies and colours. For instance, in devastated areas, the few remaining highly damaged stems are quickly accompanied by colourful herbaceous plants. These are then replaced by pioneer trees followed by nonpioneer trees of increasing size as the closure phase of the cycle continues (Fig. 9). Such cyclic effects with a succession of phases of brutal landscape opening by avalanches and progressive closure by forest recolonisation were previously highlighted in different locations (Foster and others, 1998; Kajimoto and others, 2004;Garavaglia and Pelfini, 2011). 

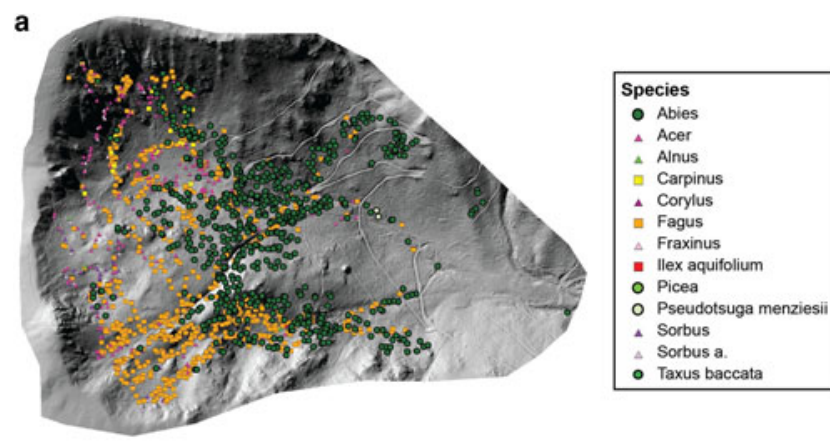

b

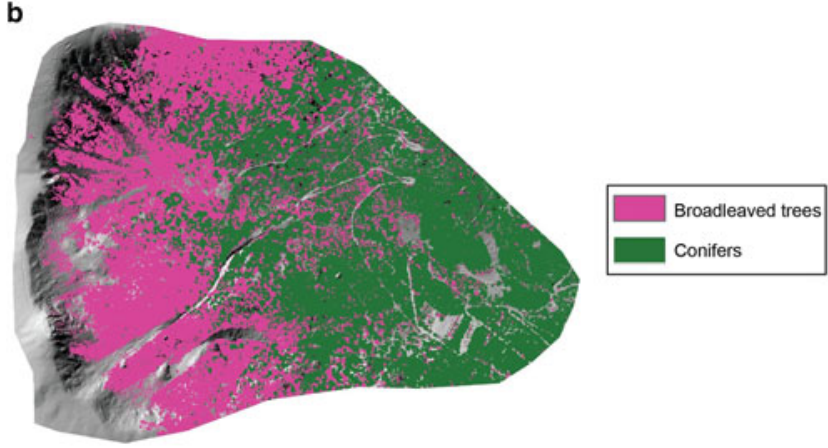

C

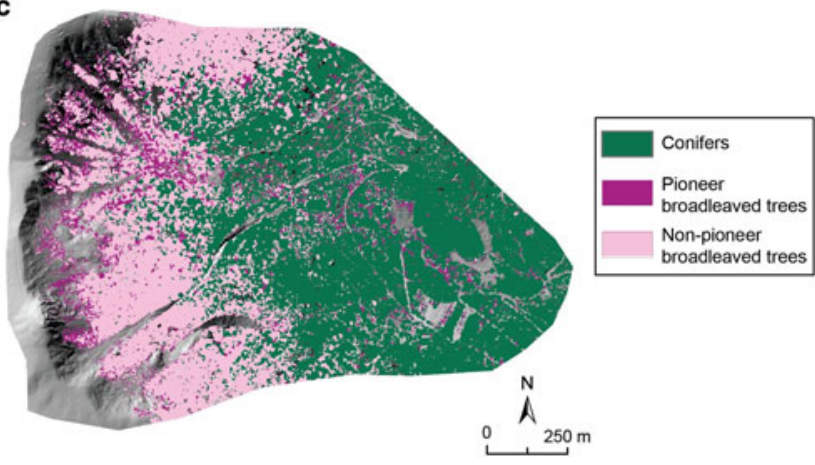

Fig. 8. Spatial distribution of tree species in the study area: (a) Trees identified by direct field investigations conducted between 2014 and 2017 (Table 4), (b) results of the 2-class classification of tree species, (c) results of the 3-class classification of tree species.

\section{Landscape evolution linked to changing human pres- sure and climate}

In the long history of resource exploitation of the Vosges Mountains, the beginning of the study period corresponds to a phase of landscape opening stemming from the combination of pressures exerted on the forests by agro-pastoral practices and proto-industrial activities consuming wood (Garnier, 2004). At the much more local scale, it is clear that the Rothenbachkopf-Rainkopf avalanche complex was particularly marked by agro-pastoralism. According to the cadastre and the État-Major map, many mountain farms were active in the immediate vicinity of the study area during the 19th century (Matter, 2010) including the Leibelthal area, which was destroyed several times by avalanches during the 19th century. This farm already existed at the beginning of the study period since it is known that there were 11 cows there in 1796 (Matter, 2010).

It was estimated that, in the Munster Valley where our study area is located, during the 1970 s 4800 ha of the surface that were no longer grazed were evolving to more or less shrubby moors (Établissement National d'Enseignement Supérieur Agronomique, 1995; Simon, 2002). This context of land abandonment and afforestation that prevailed during the study period over the Vosges Mountains is quite obvious as well for the study area. Although the cessation of pastoral activity in Leibelthal could not be precisely dated, it is certain that the 'new' farm remained in a state of ruin after the Second World War (Matter, 2010). At the same time, an impact in the study area of the reforestation policies conducted at the scale of the massif is likely, as suggested by the regular stands of young conifers we identified at elevations below $800 \mathrm{~m}$ a. s.l. Hence, changing anthropogenic pressures over the study period was clearly responsible for a dramatic forest cover evolution in the study area. We were able to document the significant elevation of the tree line since 1832 from historical maps and photographs, and the current presence of pioneer broadleaved trees was mapped in the immediate vicinity of the ridges, tangible proofs of this major landscape closure dynamics. This landscape closure resulting from agriculture abandonment and reforestation is not surprising because it has been documented in many mountain ranges in developed countries over the last two centuries. Its dynamics were of variable temporality and intensity depending on the social contexts but the phenomenon has often accelerated since the end of the Second World War (e.g. Moriniaux, 1999; Deuffic, 2005; Labrue, 2009; Spielmann and others, 2013).

These changing anthropogenic constraints on the environment may have combined with the climatic context of the late LIA. Indeed, at the beginning of the study period, regular exploitation of the area was concomitant with a colder and, to a lesser extent, less humid climate (Appendix A), which limited the extent of the forest, particularly in the upper slopes of the study area. Then gradual warming associated with a slightly wetter climate occurred at the same time as pastoral pressure decreased, which resulted in rapid afforestation. We do not exclude that the climate warming context was not necessary for the landscape closure to occur, but it seems reasonable to postulate that it has accelerated the afforestation process by creating conditions more favourable to tree colonisation and growth.

Furthermore, by decreasing snow amounts and hence the propagation of avalanche events downslope, climate warming may also have indirectly sped up the reforestation process. We cannot provide any quantitative assessment over the entire study period of natural avalanche activity response to climate change in the study area on the basis of the data available. This is because of the strong impact of historical sources on the homogeneity of avalanche records (Giacona and others, 2017b) that precludes from easily inferring avalanche-climate linkages over the long range, in the Vosges Mountains like elsewhere (e.g. Eckert and others, 2013; Ballesteros-Cánovas and others, 2018). However, our historical enquiry truly documents, despite the overall recent increase on the record, more extreme and/or highly destructive avalanches in the distant past, with no more intensity five avalanches since winter 1950/ 51, and several intensity five avalanches that caused building destructions, major forest damage and killed people during the 19th century. This is consistent with the existence of extinct avalanche sites at lower elevations in the Vosges Mountains. Such qualitative hints suggest that avalanche activity has truly decreased in the study area as the climate was warming, at least in terms of the magnitude of the events. By releasing a disturbance agent that previously limited forest colonisation of the upper slopes, this may have contributed to landscape closure in the area. 

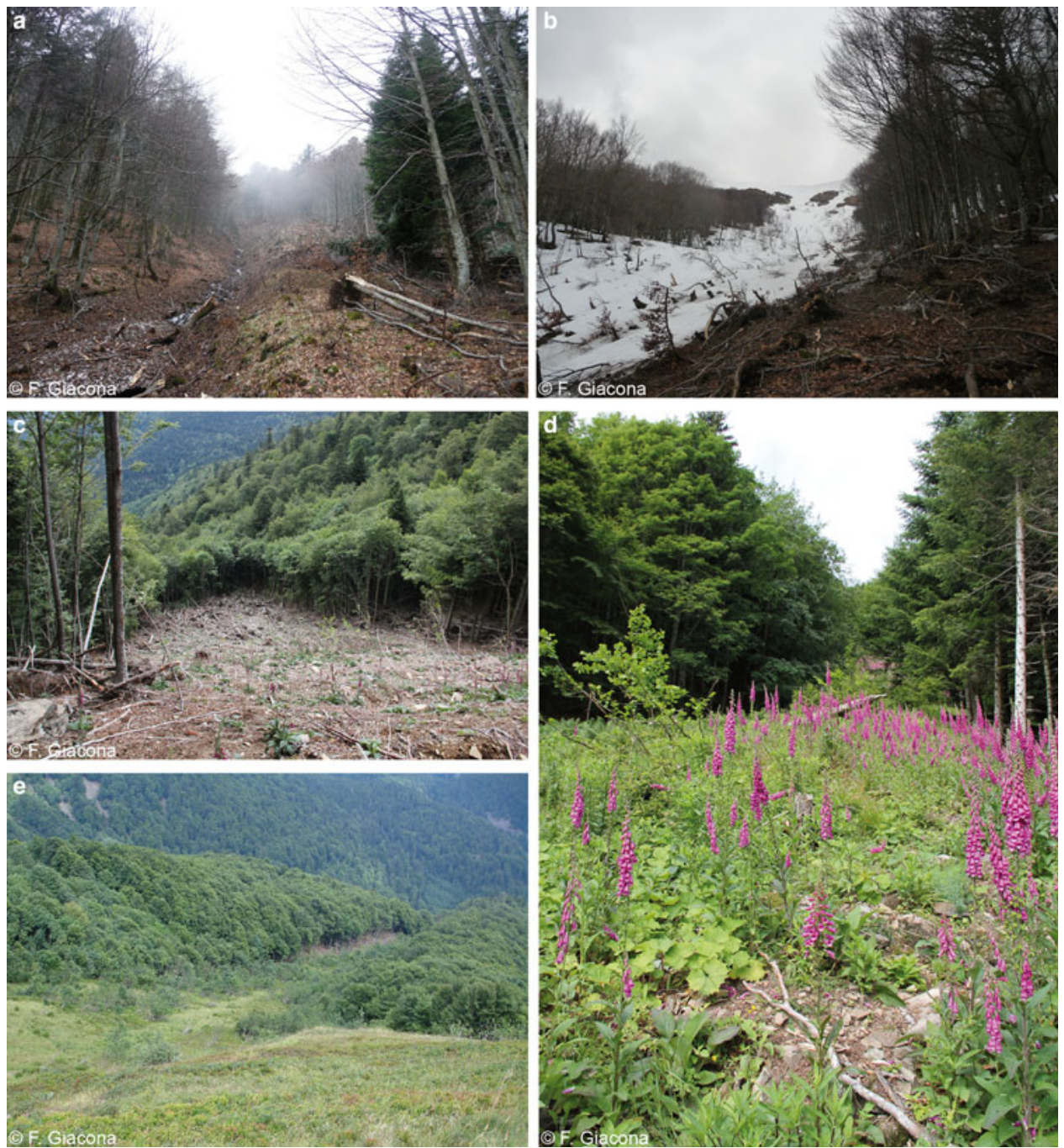

Fig. 9. Landscape footprints of the 2009/10 major avalanches in the study area: (a, b) devastated post-avalanche landscapes in spring 2010 (Couloir du Torrent - number 2); blooming Digitalis pupurea in summer 2014 in opened areas of (c) Couloir en S- number 1 and (d) Couloir du Torrent; (e) opened area and beginning of forest recolonisation in summer 2010 (Couloir du Torrent seen from the ridge).

\section{Wider relevance of the results obtained}

Even if we have never attempted to extrapolate our data outside the study area, we are convinced that similar results could have been obtained for the majority of the other nearby circuses. The Rothenbachkopf-Rainkopf complex has indeed been chosen as representative of the glacial circus constituting the eastern edge of the Vosges Mountains in terms of biophysical parameters (tree stands, geomorphology, prevailing climatic conditions, Flageollet, 2003; Goepp, 2007; Wahl and others, 2009). However, as stated above, although the social context remains broadly comparable at the scale of the entire Vosges Mountains (agro-pastoral abandonment and reforestation), local disparities (continuation, development or cessation of pastoralism and/or logging, etc.) may have caused differentiated landscape trajectories over the long term in a few specific locations. Testing these hypotheses will require reproducing the analysis with a similar methodology on other nearby areas.

Similarly, it is likely that the results obtained in terms of the landscape impact of avalanche-forest interactions remain relevant over an even wider area in temperate mountain ranges, especially medium-high ranges. For this, it is a priori only required that the slopes and the snow cover are sufficient to allow a regular avalanche activity and that the climate is mild enough to allow the development of a forest cover over a significant part of the paths, as suggested by the good agreement between our results and the already existing literature regarding forest stand organisation and avalanche activity and the opening effect of major avalanches.

In terms of long-term evolution, the climatic context of accelerated global warming over the last few decades is a worldwide reality (IPCC, 2013), but the evolution of the pressures exerted on the territory is extremely variable from one massif to another. Therefore, landscape dynamics during the last few centuries in response to avalanche activity, climate and human pressure may have been much different from one mountain range to another. Due to the current lack of quantitative studies addressing the area-wide landscape dynamics response to these three drivers combined together, comparison with other results is difficult. It can be reasonably estimated that, in many mountain ranges affected by avalanche activity, the influence of humans was less durable and less intense than in the Vosges Mountains, especially outside Europe. In such cases, the avalanche-forest interaction and climatic patterns may well be the main factors at play. However, results similar to ours could 

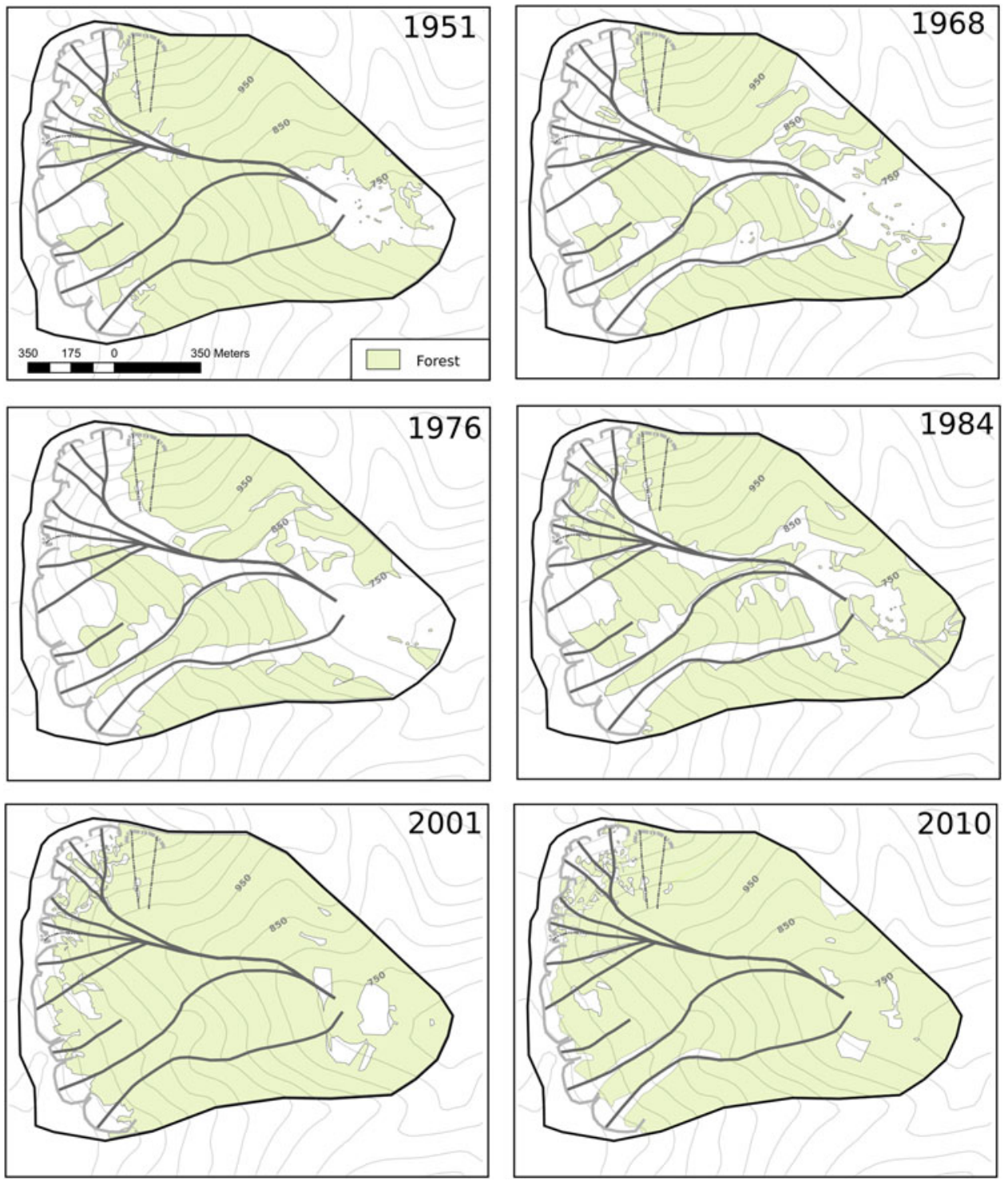

Fig. 10. Forest cover in the study area for 6 years (in black in the top-right corner) based on ortho-rectified aerial photographs.

probably be obtained in many medium-high mountain ranges of developed countries that have been submitted to the same socio-environmental changes over the last few centuries.

The profound footprints of human activity in the landscape of the Vosges Mountains are related to their long history, and hence to their rich cultural heritage. This substantially increases the complexity of landscape genesis (for instance, the 'initial state' for now appears out of reach) with regard to massifs where human influence is much less perceptible. As a corollary to such difficulties, rich information can be collected in various archives over long periods, which is impossible in barely and/or recently populated areas. The long-lasting human occupation and relatively modest size of massifs like the Vosges Mountains, therefore, make them valuable living laboratories for the study of the trajectories of socio-environmental systems over recent centuries.

\section{Pro and cons of the chosen approach and outlooks}

For the mapping of forest areas, manual digitalisation was preferred over automatic processing for both historical maps and aerial photographs. This approach was possible because of the (relatively) small size of the study area. The time necessary was, therefore, reasonable while it allowed precision that could not have been reached with an automatic procedure, in particular for the oldest topographic maps. Working both on maps and photographs to establish the diachronic evolution of the forest cover combined the strengths of the two types of sources. Estimates provided by aerial photographs are more variable from one date to another, which is related to their higher resolution. This allowed capturing detailed changes in forests, difficult to grasp from the sole analysis of topographic maps. The potential of the latter for precisely measuring the impact of avalanche activity on forest stands appeared to be more limited. However, the area-wide summary statistics (surfaces, altitudes, etc.) provided by maps and photographs over the recent period have proved to be comparable (Fig. 11). This satisfactory agreement, particularly in view of the probable low accuracy of the forest surfaces derived from the topographic maps, suggests that the latter are indeed sufficient to roughly quantify the forest evolution over the study area for the entire post-1832 period.

Also, one may express doubts regarding our tree species classification approach. In the literature (Eysn and others, 

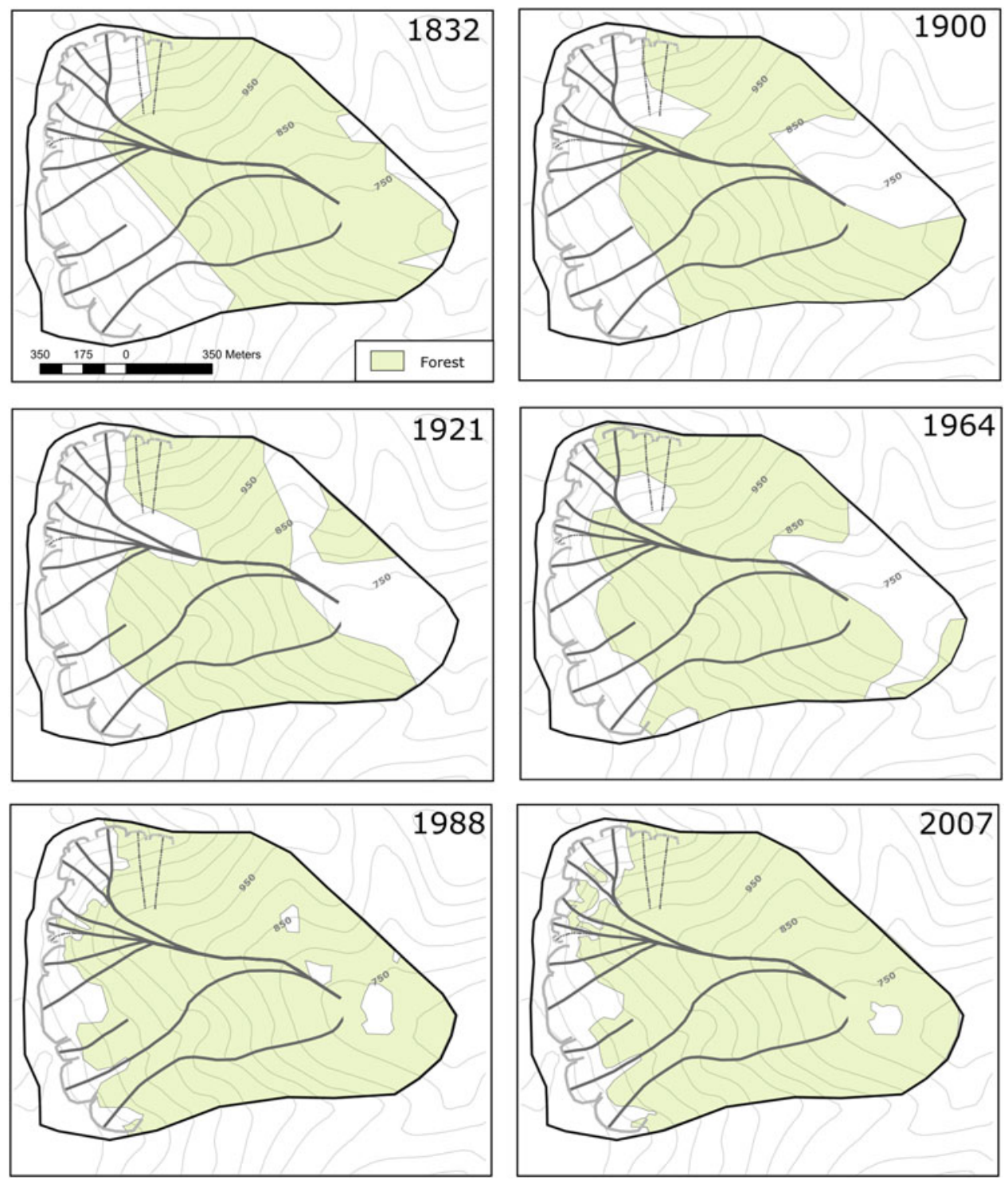

Fig. 11. Forest cover in the study area for 6 years (in black in the top-right corner) based on topographic maps. See Appendix C for details about the map editions used.

2015), this approach is known to perform well for dominant and co-dominant trees, whose crowns are visible in the CHM. Yet, field trees were sampled whatever their dominance status in the canopy, which may have lowered the classification accuracy. However, the two/three class species patterns that were obtained proved to be easy to interpret and coherent with field observations (satisfactory cross-validation scores with a large sample of tree species sampled throughout the study area, and similar spatial patterns in the field sample and classification results). We, therefore, believe that, even if locally all trees are not perfectly classified, this approach is sufficient to capture the main pattern of species distribution over the study area.

It seems possible in the near future to considerably refine the mapping of the frequency and extent of past avalanches in the study area. This improvement could be achieved using tree-ring techniques (e.g., Dubé and others, 2004; Corona and others, 2012; Schläppy and others, 2013), or, more simply, via an analysis of the spatial distribution of visible scars and stem morphologies. This was not undertaken in this study, where we limited the quantification of avalanche activity to empirical frequencies from archives at the path scale. This choice was made because the goal of this work was not refined inference of avalanche-forest interactions in the study area. Instead, the avalanche occurrence data were used to show: (i) that the zone remains currently very active and (ii) that major events in the past destroyed large forest stands, which could be linked to the forest cover evolution inferred from maps and photographs. Similarly, avalanche data helped localise avalanche paths along with field visits and topographic surveys with sufficient accuracy to understand the current patterns of tree heights and species inferred from the LIDAR survey. This is even truer given that other natural disturbances are extremely limited in the study area. All in all, characterisation of avalanche activity in the area proved sufficient to show that it is one of the drivers, among others, of the large-scale visual aspect of the complex forest landscape, both in its current state and in terms of how it has evolved over the last two and a half centuries.

In terms of the forest landscape, we concentrated on a few variables that could be evaluated throughout the study area from the data available: tree heights and species classes as a function of space for the current landscape, and the 

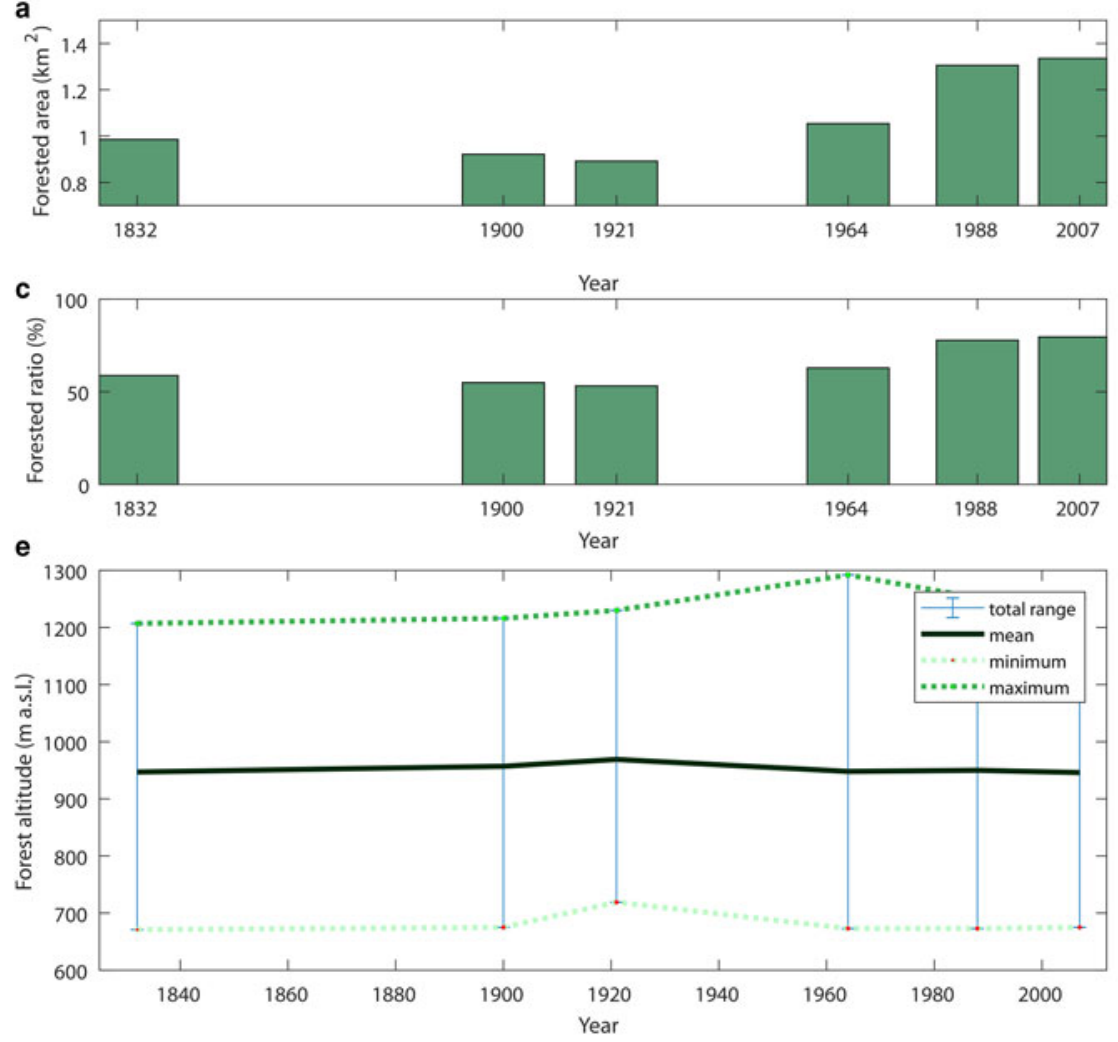

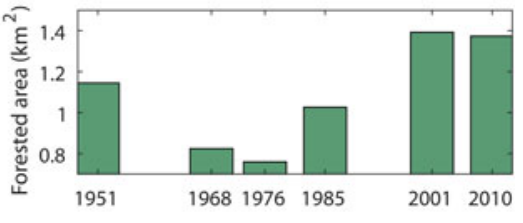

Year
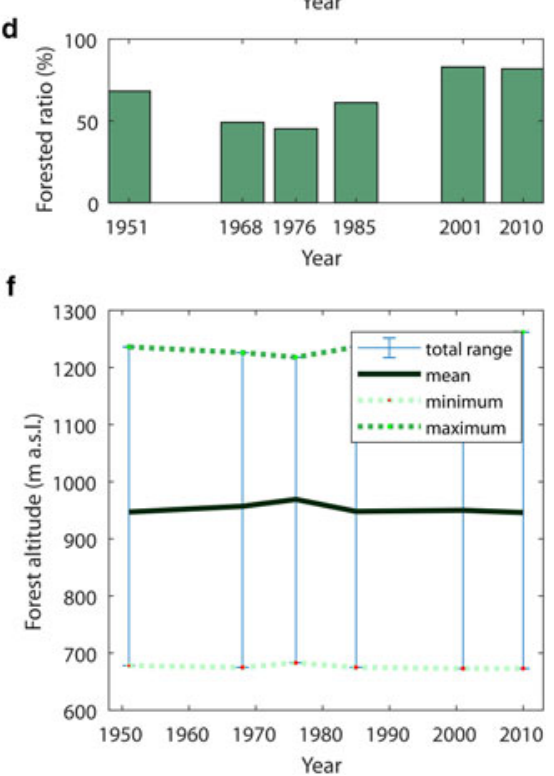

Fig. 12. Quantitative evolution of the forest stands in the study area: (a, b) forested area; (c, d) fraction of total area; (e, $f$ ) forested altitude range. Summary statistics based on topographic maps (left) and ortho-rectified aerial photographs (right).

extent of the forest cover as a function of time. Here again, we know we could have done more in terms of the smallscale study of forest stands, including a detailed analysis of the species' preferential stands, tree diameters, the percentage of living/dead individuals, the number and magnitude of visible avalanche marks as a function of, for example, the distance to avalanche paths or anthropogenic pressure, etc. However, the analysis of such metrics is beyond the scope of this paper and more difficult to conduct over the entire study area. As a consequence, the small-scale refined characterisation of the forest landscape will be part of further work in combination with additional information from tree rings regarding avalanche frequency and magnitude as a function of space.

Similarly, to quantify the respective impact of humans, avalanches and climate in the shaping the area's landscape, and how the weights of these drivers may have possibly changed over time, a complete evaluation of anthropogenic pressure (grazing pressure, forest logging), avalanche activity and climate relative to time would be required. This appears to be a challenging but appealing outlook for future study. As collateral benefits, it may provide additional useful outputs such as a more quantitative assessment of climate change impacts on snow cover and avalanches in the area. In this study, our goal was more modest: showing (i) that over the study period, humans, avalanches and climate all played a role, directly or at least indirectly, in the genesis of the forest landscape and (ii) that at a given time, the history of these drivers has been integrated by the forest landscape in its visual aspect. The length of the landscape memory is not entirely quantified, except that the time-lag of forest opening-closure cycles due to major avalanches is evaluated at $\sim 50$ years.
Finally, in this study, the relations between the components of the complex forest system under study have been apprehended only in one direction. Yet, feedback and indirect effects are actually more likely to be combined (e.g., Teich and others, 2014; Zurbriggen and others, 2014). For instance, if the avalanche activity structures forest stands, in return, these affect avalanche activity: the gradual afforestation of avalanche release zones that we have demonstrated could further reduce avalanche activity, as demonstrated by García-Hernández and others (2017) for the Asturian massif. This could, in turn, facilitate tree colonisation up to the main ridges. Hence, determining the cause and consequence is not necessarily easy. In addition to the different outlooks already listed, further progress in understanding this complexity may require simulation-based approaches of the forest ecosystem, making it possible, for example, to test different assumptions regarding its functioning and, in fine, combined with detailed modelling of the future local snow and weather drivers, provide robust predictions for the future evolution of the study area under ongoing global change.

\section{CONCLUSION}

The aim of this work was to demonstrate on a case study representative of avalanche-prone areas of the Vosges Mountains (France) that the footprints of avalanche activity, humans and climate can be retained by the landscape, and that the evolution of these drivers has been integrated into its rapid changes over more than two centuries. Clear links were established between the characteristics of the forest stands and the position of avalanche paths. Specifically, the height of individual trees and the species composition appeared to be organised 
both longitudinally and transversely to avalanche paths, in near-equilibrium with regular avalanche activity. Also, the existence of quasi-cyclic opening-closure cycles of an $\sim 50$ year periodicity was demonstrated. Induced by major avalanches, these cycles result in continuous changes in the landscape mosaic. However, the major pattern identified over the study period was a substantial afforestation of the slopes resulting in a now almost complete landscape closure. This is primarily attributable to profound changes in silvo-pastoral practices over the study period but was presumably accelerated by the impact of climate change, at least indirectly (reduction of disturbances to forest stands due to avalanche activity).

All in all, with regard to previous work conducted on snow avalanches in the Vosges Mountains (Giacona and others, $2017 \mathrm{a}, \mathrm{b})$, this study has supplemented the constitution of an avalanche chronology from historical sources with an in-depth study of the landscape genesis in a specific area. The results demonstrated the role played by different drivers, among which avalanches, which, in turn, involved documenting with higher accuracy avalanche interactions with forests and human activities in the zone. With regard to the wider existing literature, this study may have renewed the rather old topic of snow avalanches as a landscape genesis factor by choosing an area-wide approach instead of a more local analysis of interactions between avalanche activity and forest stands. Also, by focusing on a medium-high mountain range in Western Europe, additional effects due to man and climate could be considered within the same analysis. This was permitted by a combination of sources that are diverse, some of which had rarely been used for this purpose (LIDAR, etc.). Their complementarity in documenting current and past landscapes with high accuracy at the scale of the entire study area should be a guarantee of the robustness of the conclusions reached. However, this work should be reproduced in other contexts and pursued in various ways to improve our understanding of a very complex mechanics.

\section{ACKNOWLEDGEMENTS}

This work was supported by Université Grenoble Alpes (RARETES grant - avalanche risk as the revealer of longrange interactions between environment and society, AGIR-PEPS 2016 program) and by IDEX Grenoble (CrossDisciplinary Program Trajectories). We thank IGN (French National Institute of Geographic and Forest Information) for providing the LIDAR dataset. Catherine Eckert and Christophe Schoerringer are acknowledged for their logistical support during the field campaigns. Finally, the authors are grateful to Perry Bartelt and two anonymous referees, whose contributions greatly improved the paper. Irstea is a member of Labex OSUG@2020.

\section{REFERENCES}

Anderson G and McClung D (2012) Snow avalanche penetration into mature forest from timber-harvested terrain. Can. Geotech. J., 49(4), 477-484

Bebi P, Kulakowski D and Rixen C (2009) Snow avalanche disturbances in forest ecosystems-State of research and implications for management. For. Ecol. Manag., 257(9), 1883-1892

Baker WL (1992) The landscape ecology of large disturbances in the design and management of nature reserves. Landsc. Ecol., 7(3), 181-194
Ballesteros-Cánovas JA, Trappmann D, Madrigal-González J, Eckert N and Stoffel M (2018). Climate warming enhances snow avalanche risk in the Western Himalayas. Proc. Natl. Acad. Sci. U.S.A., 115(13), 3410-3415; DOI: 10.1073/ pnas. 1716913115

Benda LE, Miller DJ, Dunne T, Reeves GH and AgeeJK (1998) Dynamic landscape systems. In River ecology and management: lessons from the pacific coastal ecoregion. Springer-Verlag, New York, 261-288

Beniston M and 24 others (2018) The European mountain cryosphere: a review of its current state, trends, and future challenges. Cryosphere, 12, 759-794

Blanc C (2003) Le développement de la filière bois dans la montagne tarnaise depuis l'intervention du Fonds Forestier National: conflits et nouveaux enjeux pour la forêt (1950-2003). (DESS thesis, Université Montesquieu - Bordeaux IV), 11-23

Boyé P (1903) Les Hautes chaumes des Vosges. Étude de géographie et d'Économie historique. Berger-Levrault et Cie, Paris, $432 p$

Brun A (1978) Concurrence agriculture-forêt en moyenne montagne: une responsabilité locale. Économie Rurale, 127, $54-57$

Burrows CJ and Burrows VL (1976) Procedures for the study of snow avalanche chronology using growth layers of woody plants. Colorado University Institute of Arctic and Alpine Research, Occasional paper, 23, 54p

Butler DR (1979) Snow avalanche path terrain and vegetation. Glacier National Park, Montana. Arct. Alp. Res., 11(1), 17-32

Butler DR and Malanson GP (1985) A reconstruction of snow-avalanche characteristics in Montana, USA, using vegetative indicators. J. Glaciol., 31(108), 185-187

Butler DR and Walsh SJ (1990) Lithologic, structural, and topographic influences on snow-avalanche path location, Eastern Glacier National Park, Montana. Ann. Assoc. Am. Geographers, 80(3), 362-378

Casty C, Raible CC, Stocker TF, Luterbacher J and Wanner H (2007) A European pattern climatology 1766-2000. Clim. Dyn., 29, 791-805. DOI: 10.1007/s00382-007-0257-6

Collomb E (1848) Nouvelles observations faites sur un petit glacier temporaire des Vosges en janvier et février 1848. Bibliothèque Universelle, Genève, $23 p$

Corona C and 6 others (2012) How much of the real avalanche activity can be captured with tree rings? An evaluation of classic dendrogeomorphic approaches and comparison with historical archives. Cold Reg. Sci. Technol., 74, 31-42

Decaulne A, Eggertsson Ó, Laute K and Beylich AA (2014) A 100 -year extreme snow-avalanche record based on tree-ring research in upper Bødalen, inner Nordfjord, western Norway, Geomorphology, 218, 3-15

Deuffic P (2005) La fermeture des paysages dans le Massif Central: regards d'habitants sur une question d'experts. Cahiers d'économie et sociologie rurales, 75, 76-96

Dion J (1985) Les forêts vosgiennes. Étude biogéographique. Aux amateurs de livres, Paris, $484 \mathrm{p}$

Drogue G, Wagner C, Mahr N, Hoffmann L and Pfister L (2006) Topography and recent winter rainfall regime change in temperate Western European areas: a case study in the Rhine-Meuse basin. Int. J. Climatol., 26(6), 785-796

Dubé S, Filion L and Hétu B (2004) Tree-ring reconstruction of highmagnitude snow avalanches in the Northern Gaspé Peninsula, Québec, Canada. Arct. Antarct. Alp. Res., 36(4), 555-564

Eckert N, Keylock CJ, Castebrunet H, Lavigne A and Naaim M (2013) Temporal trends in avalanche activity in the French Alps and subregions: from occurrences and runout altitudes to unsteady return periods. J. Glaciol., 59(213), 93-114

Établissement national d'enseignement supérieur agronomique (1995) Pays, paysans, paysages dans les Vosges du Sud: les pratiques agricoles et la transformation de l'espace. INRA, Paris, 1-32

Eysn L and 10 others (2015) A benchmark of lidar-based single tree detection methods using heterogeneous forest data from the alpine space. Forests, 6(5), 1721-1747 
Favillier A and 9 others (2018). Spatio-temporal maps of past avalanche events derived from tree-ring analysis: a case study in the Zermatt valley (Valais, Switzerland), Cold Reg. Sci. Technol., 154, 9-22

Feistl T and 6 others (2014) Observations and modeling of the braking effect of forests on small and medium avalanches. J. Glaciol., 60(219), 124-138

Feistl T and 5 others (2015) Forest damage and snow avalanche flow regime, Nat. Hazards Earth Syst. Sci., 15, 1275-1288

Flageolet JC (2005) Ou sont les neiges d'antan? Deux siècles de neige dans le Massif vosgien. Presses universitaires de Nancy, Nancy, $220 p$

Flageollet JC (2003). Sur les traces des glaciers vosgiens. CNRS Éditions, Paris, 212p

Foster DR, Knight DH and Franklin JF (1998) Landscape patterns and legacies resulting from large, infrequent forest disturbances. Ecosystems, 1(6), 497-510

Garavaglia V and Pelfini M (2011) The role of border areas for dendrochronological investigations on catastrophic snow avalanches: a case study from the Italian Alps, Catena, 87(2), 209-215

García-Aguirre MC, Álvarez R and Aceves F (2012) Geology and geomorphology in landscape ecological analysis for forest conservation and hazard and risk assessment, illustrated with Mexican case histories. Earth Sci.

García-Hernández C and 5 others (2017) Reforestation and land use change as drivers for a decrease of avalanche damage in mid-latitude mountains (NW Spain). Glob. Planet Change, 153, $35-50$

Garnier E (1998) Jalons pour une histoire de l'environnement: la Réserve naturelle du Frankenthal-Missheimle. Relations des sociétés et du milieu. Munster, PNRBV, 1-39

Garnier E (2004) Terre de conquêtes. La forêt vosgienne sous l'Ancien Régime. Fayard, Paris, 2, 620p

Giacona F, Eckert N and Martin B (2017a) La construction du risque au prisme territorial: dans l'ombre de l'archétype alpin, les avalanches oubliées de moyenne montagne. Nat. Sci. Sociétés, 25 (2), 148-162

Giacona F, Eckert N and Martin B (2017b) A 240-year history of avalanche risk in the Vosges Mountains based on non-conventional (re)sources, Nat. Hazards Earth Syst. Sci., 17, 887-904

Glaser R and Riemann D (2009) A thousand-year record of temperature variations for Germany and Central Europe based on documentary data. J. Quat. Sci., 24, 437-449

Goepp S (2007) Origine, histoire et dynamique des Hautes-Chaumes du massif vosgien. Déterminisme environnementaux et actions de I'Homme. (PhD Thesis, Université Louis Pasteur -Strasbourg I), 288p

Grad C (1871) Observations sur les petits glaciers temporaires des Vosges. Bulletin de la Société d'Histoire Naturelle de Colmar, Colmar, 207-213

Grove JM (1988) The little ice age. Taylor \& Francis, London and New York, 524p

Heath JP (1960) Repeated avalanches at Chaos Jumbles, Lassen Volcanic National Park, California. Am. J. Sci., 258(10), 744-751

Hétu B, Fortin G and Brown K (2015). Climat hivernal, aménagement du territoire et dynamique des avalanches au québec méridional: Une analyse à partir des accidents connus depuis 1825. Can. J. Earth Sci., 52(5), 307-321

IPCC (2013) In Contribution of Working Group I to the Fifth Assessment Report of the Intergovernmental Panel on Climate Change. Stocker TF, Qin D, Plattner G-K, Tignor M, Allen SK, Boschung J, Nauels A, Xia Y, Bex V and Midgley PM eds. Climate change 2013: the physical science basis. Cambridge University Press, Cambridge, UK and New York, USA, 1535p

Jéhin P (1993) Les hommes contre la forêt. L'exploitation des forêts dans le Val d'Orbey au XVIIle siècle. La Nuée Bleue, Strasbourg, 205p

Jéhin P (2010) Verriers et forêts sous I'Ancien Régime en Alsace. Les actes du CRESAT, 7, 49-58
Johnson EA (1987) The relative importance or snow avalanche disturbance and thinning on canopy plant populations. Ecology, 68(1), 43-53

Kajimoto T, Daimaru H, Okamoto T, Otani T and Onodera H (2004) Effects of snow avalanche disturbance on regeneration of subalpine Abies mariesii forest, northern Japan. Arct. Antarct. Alp. Res., 36(4), 436-445

Kammerer O (2003) Les Vosges sont-elles une montagne au Moyen Age? Actes des congrès de la Société des historiens médiévistes de l'enseignement public supérieur, $34{ }^{\text {ème }}$ congrès, Chambéry, 23-39

Koerner W (2000) Evolution des surfaces boisées en France depuis le début du XIXe siècle: identification et localisation des boisements des territoires agricoles abandonnés. Revue Forestière Française, 3(52), 249-270

Krause D and K'ŕížek M (2018). Dating of recent avalanche events in the Eastern High Sudetes, Czech Republic, Quat. Int., 470, 166-175

Kulakowski D, Rixen C and Bebi P (2006) Changes in forest structure and in the relative importance of climatic stress as a result of suppression of avalanche disturbances. For. Ecol. Manag., 223(1), 66-74

Kulakowski D, Bebi P and Rixen C (2011) The interacting effects of land use change, climate change and suppression of natural disturbances on landscape forest structure in the Swiss Alps. Oikos, 120(2), 216-225

Kulakowski D, Barbeito I, Casteller A, Kaczka R and Bebi P (2016) Not only temperature: interacting drivers of treeline change in Europe, Geogr. Pol., 89(1), 7-15

Labrue C (2009) Le massif, ses marges et la préoccupation d'enfermement de l'habitat. Exemple des Vosges du Nord. Revue de Géographique de l'Est, 49(2-3), 15p

Léser G. (1995) La conquête des Hautes Chaumes par les marcaires de la vallée de Munster. Dialogues Transvosgiens, 10, 56-60

Luckman BH (1977) The geomorphic activity of snow avalanches. Geografiska Annaler, Ser. A Phys. Geogr., 59(1-2), 31-48

Malanson GP and Butler DR (1984) Transverse pattern of vegetation on avalanche paths in the northern Rocky Mountains, Montana. Great Basin Naturalist, 44(3), 453-458

Malanson GP and Butler DR (1986) Floristic patterns on avalanche paths in the northern Rocky Mountains, USA. Phys. Geography, 7(3), 231-238

Maggioni M and Gruber U (2003) The influence of topographic parameters on avalanche release and frequency. Cold Reg. Sci. Technol., 37, 407-419

Marthelot P (1952) Notes sur l'état actuel et sur les mesures de restauration des Hautes-Chaumes des Vosges. Géocarrefour, 27 (2) $173-179$

Matter J (2010) Du Glasborn au Schoenenklang. Chronique des marcairies de la Vallée de Munster, 1490-1847. J. Do Bentzinger Colmar, $133 p$

McClung DM (2003) Magnitude and frequency of avalanches in relation to terrain and forest cover. Arct. Antarct. Alp. Res., 35 (1), 82-90

Minárová J. (2013) Climatology of precipitation in the Vosges Mountain range area. Auc Geographica, 48(2), 51-60

Moriniaux V (1999) Les Français face à l'enrésinement. XVle-XXe siècles. (Thèse de doctorat (Géographie), Université ParisSorbonne, Paris), 348p

Patten RS and Knight D (1986) Snow avalanches and vegetation pattern in cascade canyon, grand teton national park. University of wyoming national park service research center. Annu. Rep., 10(1), 104-119

Patten RS and Knight DH (1994) Snow avalanches and vegetation pattern in cascade canyon, grand teton national park, wyoming, USA. Arct. Alp. Res., 26(1), 35-41

Pfister C (1992) Monthly temperature and precipitation patterns in Central Europe from 1525 to the present. A methodology for quantifying man made evidence on weather and climate. In Bradley RS and Jones PD eds. Climate since 1500 A.D., 118-143

Rieutort L (1997) Les moyennes montagnes d'Europe occidentale: affaiblissement ou réadaptation des campagnes?. NOROIS, 
Revue géographique de l'Ouest et des pays de l'Atlantique Nord, 173(1), 61-83

Rixen C, Haag S, Kulakowski D and Bebi P (2007) Natural avalanche disturbance shapes plant diversity and species composition in subalpine forest belt. J. Veg. Sci., 18(5), 735-742

Schaerer PA (1973) Terrain and vegetation of snow avalanche sites at rogers pass, British Columbia. In Slaymaker $\mathrm{HO}$ ed. Mountain geomorphology: geomorphological processes in the Canadian Cordillera. B. C. Geographical series, 14, 215-222

Schläppy R and 7 others (2013) A New tree-ring based, semi-quantitative approach for the determination of snow avalanche events: use of classification trees for validation. Arct. Antarct. Alp. Res., 45(3), 383-395

Schönenberger W, Noack A and Thee P (2005) Effect of timber removal from windthrow slopes on the risk of snow avalanches and rockfall. For. Ecol. Manag., 213(1), 197-208

Schumacher S and Bugmann $\mathrm{H}$ (2006) The relative importance of climatic effects, wildfires and management for future forest landscape dynamics in the Swiss Alps. Glb. Chg. Bio., 12(8), 1435-1450

Sgard A (2007) La montagne: objet scientifique ? Objet politique ? in Fourny M-C, Sgard A, Morel A, Bocquet G, Gumuchian H and Vallade O eds. Ces géographes qui écrivent les Alpes. Une relecture de la Revue de Géographie alpine à travers le siècle. Revue de Géographie alpine, Grenoble, 11-48

Šilhán K and Tichavský R (2017). Snow avalanche and debris flow activity in the high Tatras Mountains: new data from using dendrogeomorphic survey, Cold Reg. Sci. Technol., 134, 45-53

Simo A (2002) La pluriactivité dans l'agriculture des montagnes françaises. Un territoire, des hommes, une pratique. CERAMAC, Presses universitaires Blaise Pascal, Clermont-Ferrand, 233-252

Simonson S, Stohlgren T, Landry C and Fassnacht S (2008) Snow avalanche path ecology: examples from the San Juan Mountains, Colorado. In Proceedings whistler 2008 international snow science workshop, September 21-27, 800

Spielmann M, Bücking W, Quadt V and Krumm F (2013) Integration of nature protection in forest policy in Baden-Württemberg (Germany). INTEGRATE Country Report, EFICENT-OEF, Freiburg, 78p

Stoffel M and Bollschweiler M (2008) Tree-ring analysis in natural hazards research? An overview. Nat. Hazards Earth Syst. Sci., 8 (2), 187-202

Stoffel M and Corona C (2014) Dendroecological dating of geomorphic disturbance in trees. Tree-Ring Res., 70(1), 3-20

Takeuchi Y, Torita H, Nishimura K and Hirashima H (2011) Study of a large-scale dry slab avalanche and the extent of damage to a cedar forest in the Makunosawa valley, Myoko, Japan, Ann. Glaciol., 52, 119-128

Teich M, Bartelt P, Gret-Regamey A and Bebi P (2012) Snow avalanches in forested terrain: influence of forest parameters, topography, and avalanche characteristics on runout distance. Arct. Antarct. Alp. Res., 44, 509-519

Teich $M$ and 5 others (2014) Computational snow avalanche simulation in forested terrain. Nat. Hazards Earth Syst. Sci., 14(8), 2233-2248

Veblen TT and 5 others (1994) Disturbance regime and disturbance interactions in a Rocky Mountain subalpine forest. J. Ecol., 82(1), 125-135

Viglietti D, Letey S, Motta R, Maggioni M and Freppaz M (2010) Snow avalanche release in forest ecosystems: a case study in the Aosta valley region (NW-Italy). Cold Reg. Sci. Technol., 64(2), 167-173

Voiculescu M and Ardelean F (2012) Snow avalanche-disturbance of high mountain environment. Case study-the Doamnei glacial valley the Făgăraş massif-Southern Carpathians, Romanian Carpathians. Carpathian J. Earth Environ. Sci., 7(1), 95-108

Wahl L, Planchon O and David PM (2007) Névés, corniches et risque d'avalanche dans les Hautes-Vosges. Revue Géographique de I'Est, 47(4). URL: http://journals.openedition.org/rge/1533

Wahl L, Planchon O and David PM (2009) Characteristics and seasonal evolution of firns and snow cornices in the high Vosges mountains (eastern France). Erkunde, 63(1), 51-67

Walsh SJ, Butler DR, Brown DG and Ling B (1990) Cartographic modeling of snow avalanche path location within Glacier
National Park, Montana. Photogramm. Eng. Remote. Sensing., 56(5), 615-621

Walsh SJ, Butler DR, Allen TR and Malanson GP (1994) Influence of snow patterns and snow avalanches on the alpine treeline ecotone. J. Veg. Sci., 5(5), 657-672

Walsh SJ, Weiss DJ, Butler DR and Malanson GP (2004) An assessment of snow avalanche paths and forest dynamics using Ikonos satellite data. Geocarto. Int., 19(2), 85-93

Zurbriggen N, Nabel JE, Teich M, Bebi P and Lischke H (2014) Explicit avalanche-forest feedback simulations improve the performance of a coupled avalanche-forest model. Ecol. Complex., 17, 56-66

\section{APPENDIX A CLIMATE CONTEXT OF THE GREATER STUDY AREA}

The longest instrumental series of meteorological observations close to the Vosges Mountains is the observation of Basel, Switzerland, available free at http://www.ncdc.noaa. gov/data-access/paleoclimatology-data. The annual average temperature signal (Fig. 13a) clearly shows, beyond its interannual variability, the sharpness of the PAG signal before 1900 (the 15-year moving average is almost constantly below $9^{\circ} \mathrm{C}$, with decades particularly cold $\sim 1810$ and $1850)$ as well as the intense warming that followed $\left(\sim+1^{\circ} \mathrm{C}\right.$ over the 1900-1950 period). Other available point station data from the surrounding area (not shown) and Pfister's regional indexes (Fig. 13b) confirm this signal $(R=0.94$ between annual values of Pfister's temperature index and temperatures in Basel, $R=0.97$ between moving averages over 15 years, both values significant at the $0.05 \%$ level on the basis of a Student test). Pfister's precipitation index (Fig. 13c) suggests that, at the regional level, the concomitant
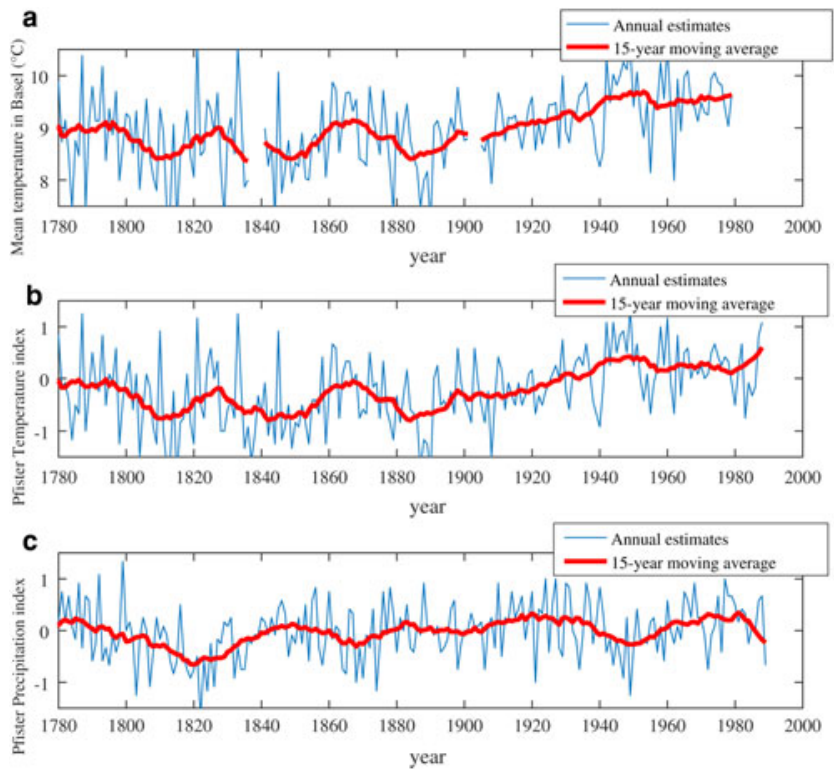

Fig. 13. Mean annual temperature and precipitation: (a) temperature in Basel, Switzerland; Pfister's temperature (b) and precipitation (c) indexes. Annual values were computed from the available monthly data covering October to September periods. For example, the 1900 value corresponds to the mean of October 1900 to September 1901 monthly values. Pfister's indexes are monthly values between -3 and 3 evaluated from various historical sources and are valid for Central Europe. 0 represents an average behaviour, -3 an extremely cold/dry value compared with the average, and +3 an extremely hot/humid value compared with the average. 
evolution towards a wetter climate generally attributed to the PAG termination (Grove, 1988) existed, but that it has been very slight ( $R=0.25$ between 15-year moving averages of Pfister's temperature and precipitation indexes, significant at the $0.05 \%$ level on the basis of a Student test).

\section{APPENDIX B}

\section{EXAMPLE OF HISTORICAL MAPS AND AERIAL}

PHOTOGRAPHS SUPPORTING THE DIACHRONIC

\section{ANALYSIS}

See Fig. 14

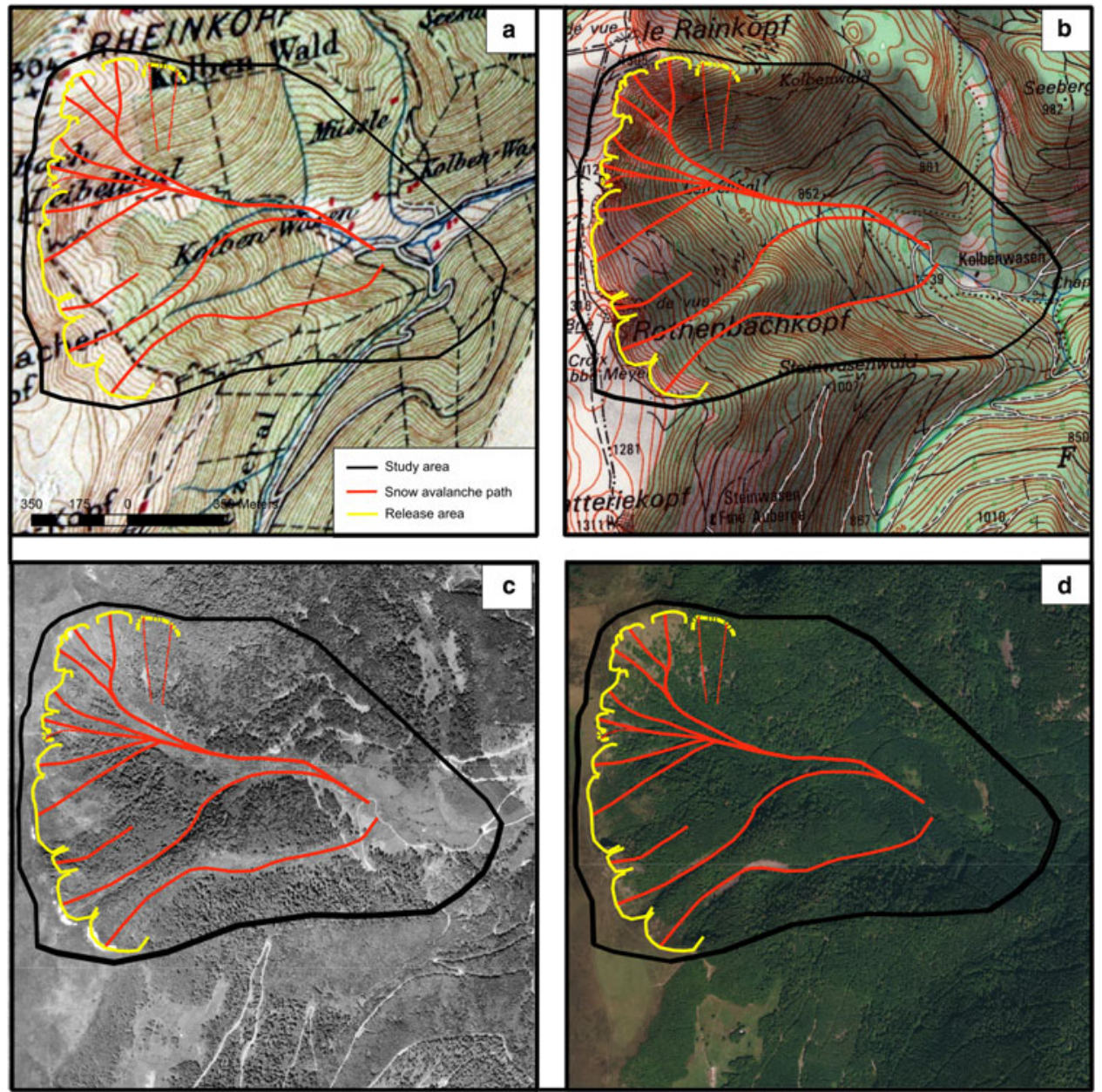

Fig. 14. (a) German map of 1900 (Karl Flemming Mapping Institute), (b) French map of 1988 (Club Vosgien), ortho-rectified aerial photographs of (c) 1968 and (d) 2010 (French National Geographical Institute). Snow avalanche release areas, flow paths and the study area (cf. Fig. 1) are plotted on the different maps and photographs. 


\section{APPENDIX C}

See Table 5.

Table 5. Set of maps used to document the evolution of forest cover in the study area

\begin{tabular}{|c|c|c|c|c|c|c|}
\hline & Publisher & Source & Map name & Scale & Year of survey & Year of edition \\
\hline 1832 & IGN (Etat Major map) & IGN & Epinal & 1: 40000 & 1832 & NA \\
\hline 1900 & Kartographiches Institut von Karl Flemming & Strasbourg National Library & Wildenstein & 1: 50000 & NA & 1900 \\
\hline 1921 & NA & Strasbourg National Library & Wildenstein & 1: 50000 & NA & 1921 \\
\hline 1964 & Club Vosgien & Club Vosgien & Thann-Guebwiller & 1: 50000 & 1964 & 1968 \\
\hline 1988 & Club Vosgien & Personal fund & $\begin{array}{l}\text { Honneck - Petit } \\
\quad \text { Ballon - Trois Epis }\end{array}$ & 1: 25000 & NA & 1988 \\
\hline 2007 & IGN & IGN & / & 1: 25000 & NA & 2007 \\
\hline
\end{tabular}

\section{APPENDIX D \\ HISTORICAL SOURCES REFERRING TO MAJOR AVALANCHES OF THE PAST IN THE STUDY AREA}

See Table 6.

Table 6. Description by historical sources of avalanches that caused severe damage to forest stands during the winters 1846/47, 1907/08 and 1950/51. Original texts are either in French or German, according to the complex history of the study area

Winter Event (s) description Source (s)

1846/47 One of these avalanches (...) removed a band covering several Letter from E. Collomb to the foreign secretary, Bulletin de la Société hectares of fir and beech forests. The ground is completely denuded, laid bare: not a tree remained standing all along the line travelled, and there were a fairly high number of largecalibre trees, which suggests that the avalanche descended at a fairly high speed (...). The distance travelled is, in a straight line, $1500 \mathrm{~m}$, and the average slope is $46 \%$

1907/08 For example, an avalanche of $\sim 15000 \mathrm{~m}^{3}$ of snow has recently fallen in the Rothenbach valley, knocking down a piece of forest and twisting strong trunks

Trunks with a thickness of 2-3 m are encased in snow. Writers of these times and other people who saw them estimate the size of the avalanche at $10000-15000 \mathrm{~m}^{3}$ of snow

1950/51 The overall estimate of the devastated area covers $\sim 20$ ha. The exploitation of timber torn out by avalanches will last more than 2 years for a volume of exactly $2890 \mathrm{~m}^{3}$. It will be prepared under very difficult conditions. The avalanches brought with it boulders, mud and soil. Until the 90s, we could still see roots from the fir trees torn off by avalanches in the back of the Kolbenwasen

The avalanche was released at the Rothenbachkopf, at $1200 \mathrm{~m}$ altitude, descending in two tongues to the bottom of the Mittlach valley. According to some people, the snow flow travelled nearly two kilometers. Marcel Neff, a former lumberjack in Mittlach, remembers the precise dimension of one of the snow tongues: $890 \mathrm{~m} \times 170 \mathrm{~m}$... The avalanche stopped just behind the Kolben farm where there was livestock Great amounts of snow washed down and carried away a whole parcel of fir trees from the Metzeral forest to the bottom of the Kolben. The tree trunks were broken and scattered pell-mell on the ground. About $20000 \mathrm{~m}^{3}$ of fir trees were annihilated. The horribly mutilated trunks had to be sold later at low prices Fifty-year-old fir trees measuring $70 \mathrm{~cm}$ in diameter were broken off like match sticks and carried to the valley with uncanny force. (...) The avalanche cone of the great avalanche covers more than 1 ha of ground and is almost indescribable. Altogether, about 10 ha of high forest were completely destroyed by the two avalanches and $\sim 300 \mathrm{~m}^{3}$ of logs, broken into pieces, were carried to the valley'

Letter from E. Collomb to the foreign secretary, Bulletin de la Soci
Géologique de France, deuxième série, Paris, Imprimerie de

L. Martinet, 1847

Frühling im Munsterthal, 31 mai 1908, Die Vogesen, no 10, 1908

Der Bote vom Munsterthal, newspaper, 19 April 1908 edition

Boithiot, A. (2001). Les avalanches du Rothenbachkopf, février 1952, DialoguesTransvosgiens, vol. 16

Mémoire des avalanches à Mittlach, L'Alsace, newspaper, 24 February 1999 edition

La vallée de Munster est, en certains endroits, également exposée aux dangers d'avalanche, Dernières Nouvelles d'Alsace, newspaper, 13 February 1970 edition

In den Hochvogesen wurden durch die Schneefälle zahlreiche Strassen gesperrt, Dernières Nouvelles d'Alsace, newspaper, 14 February 1952 edition 